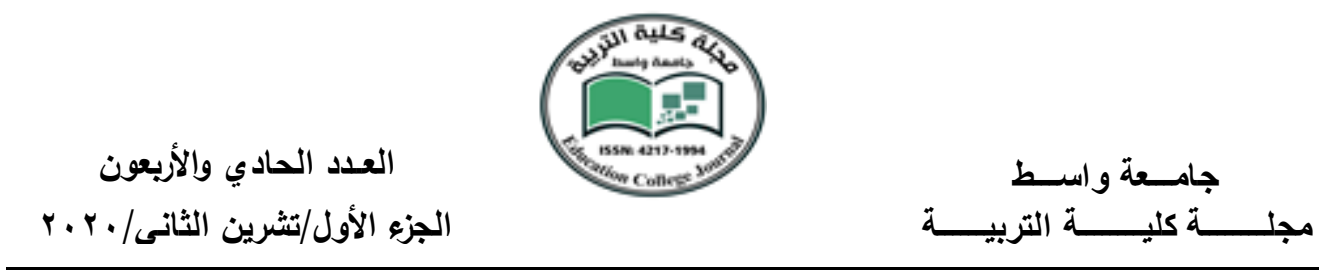

\title{
السلالم في عمارة بلاد الرافدين \\ " دراسة تحليلية في ضوء نتائج التنقيبات "
}

أ.م.د. محمد سياب محان

جامعة القادسيـة / كلية الاثار

mohammed_sayyab@yahoo.com

الملخص

يعد السلم أحد العناصر المهمة التي نكمل المباني القديمة ، ولا يعرف بدايات استخدامه

تحديدا في مجال العمارة ، إلا أنه من خلال الاكتشافات الأثرية وجد أن الإنسان استرشد بإنشاء هذا

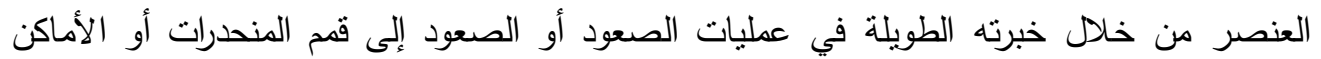
المرتقعة ، وهو ما يحتاجه الجهد العضلي في الوصول إلى قمم هذه المنحدرات أوالوصول إلى قمة المباني التي بناها. لذلك ، تُكمن أهمية هذا العنصر في حقيقته أنه سنهل عملية التسلق إلى أعلى الأسطح والمباني ذات المدرجات. لللك ، مع مرور الوقت ، أظهرت العمارة أهمية هذا العنصر وضرورته في البناء.

الكلمات المفتحية: سلم في ألم عمارة ، بيوت سكن ، سطوح ،

\section{Ass.prof Dr . Mohammed seiab Mahan University of Al-Qadisiyha/College of Archeology}

\section{Summary}

The ladder is one of the important elements that complement the ancient buildings, and it is not known the beginnings of its use specifically in the field of architecture, except that through archaeological discoveries it was found that man was guided by the creation of this element through his long experience of the processes of ascending or ascending to the tops of cliffs or high places, which he needed effort Muscular is great at reaching and reaching the tops of these slopes and on top of the buildings he built. Therefore, the importance of this element lies in the fact that it facilitated the process of climbing to the top of roofs, buildings with terraces and terraces. So, with the passage of time, architecture showed the importance of this element and its necessity in building . 


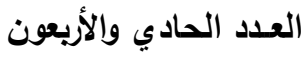

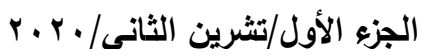

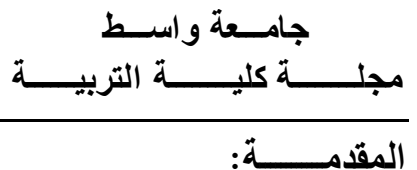

تعتبر إنجازات العراقيين القدماء في العمارة كثيرة، وكان من جملة إبداعاتهم مقدرتهم العالية

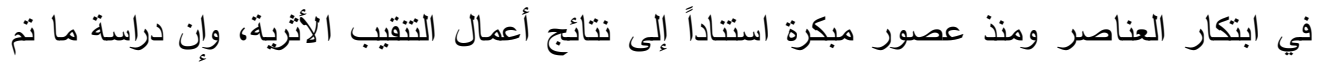
الكثف عنه من هياكل عمارية في المواقع القديمة، والتي نرتقي إلى عصور ما قبل التأريخ وتحليلها

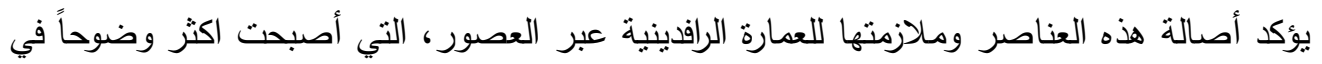

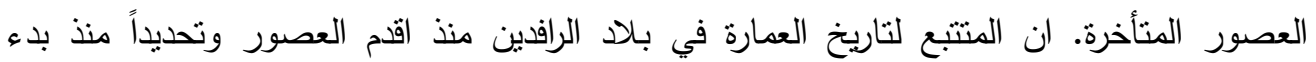

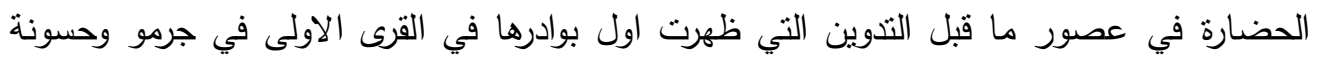
وسامراء وحلف والعبيد، يجد ان العمارة قد مرت بسلسلة من التحولات المعمارية سواء كانت تلك فلك العمارة مدنية تشمل بيوت السكن، اذ اشارت المصادر التاريخية ان العمارة بوصفها فناً متكاملاً وقائماً

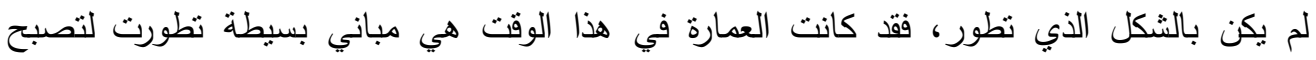

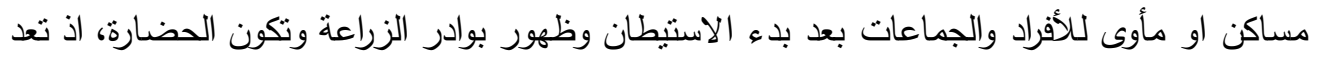
اقدم اشكال او مظاهر العمارة هي مبانٍ لمساكن في عصر حسونة يعود تاريخها الى حوالي ... ل1ه

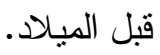

ان السلم من العناصر المهمة المكلة للأبنية القديمة، ولا يعرف بدايات استخدامه تحديداً في مجال

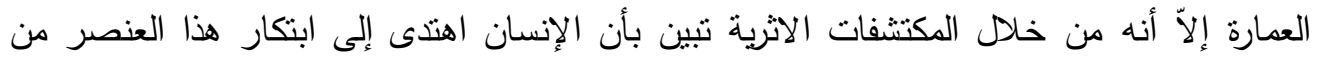

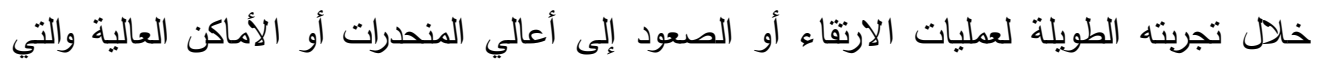

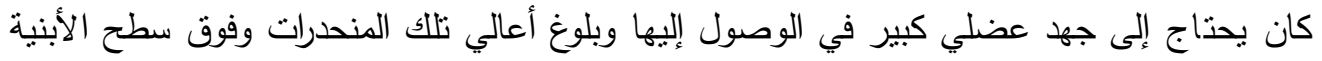

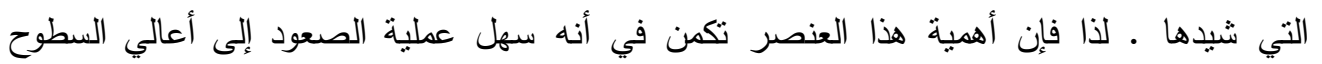

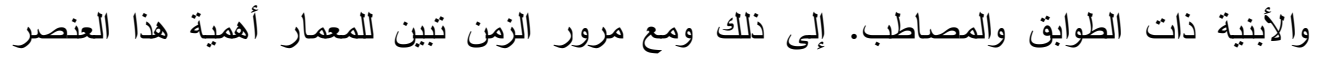

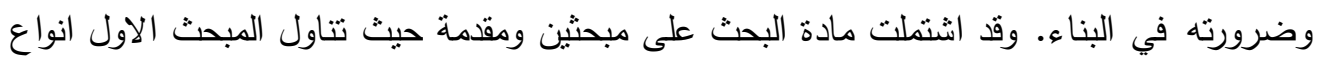

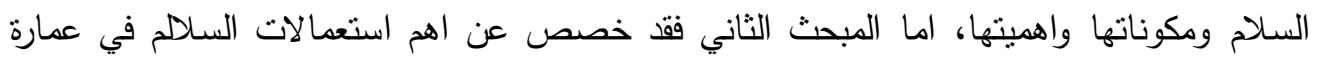

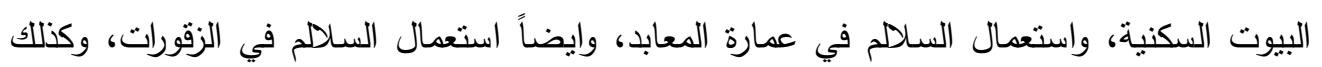
استعمالات السلم في عمارة القبور والقصور . 
العدد الحادي والأليعون

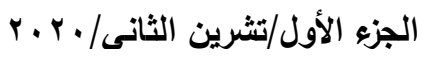
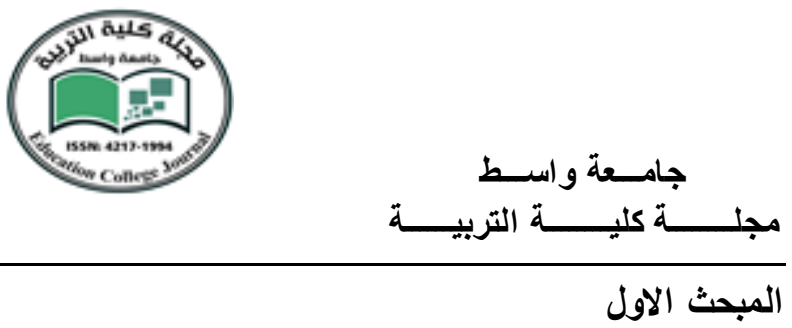

انواع السلالم ومكوناتها وا هميتها

اولاً: السلم لغة واصطلاحاً

سميت السلالم بتسميات عدة منها الريم والمراهص والمعرج والمصعد والمرقاة والسلم أو الدرج، والدرج هو السلم الذي يتخطى عليه من الأسفل إلى الأعلى '. والسلم هو ما يكون الصعود عليه سواء كان

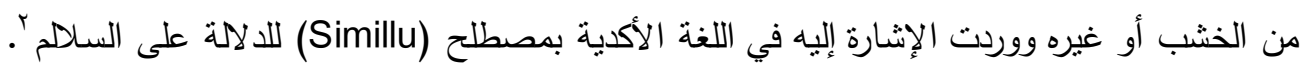
ثانياً: انواع السلالم تختلف أنواع السلالم من حيث الاستخدام وان المعمار لم يبخل مما لديه من أفكار وتصاميم لكي

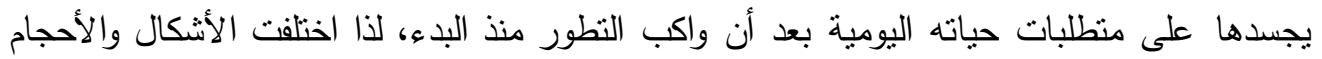

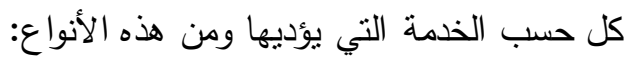

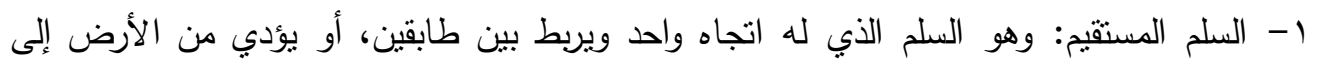

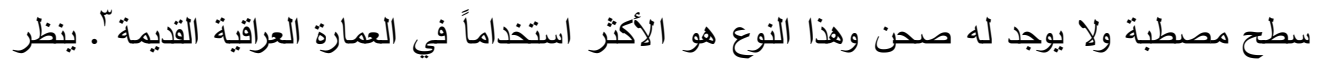

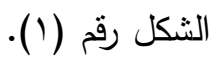
r- السلم الدستقيم النصفي: وهو السلم الذي يكون فيه الصحن في الوسط، والذي بربط بين جزأي

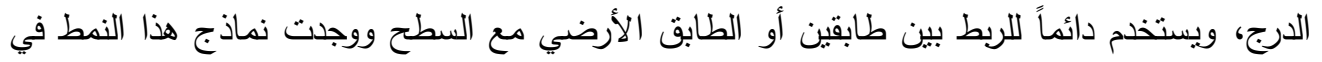

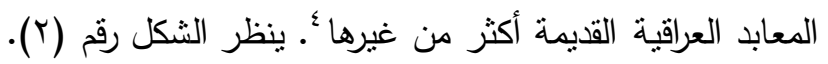

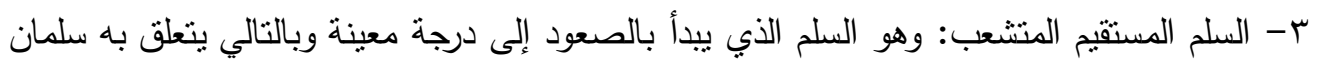

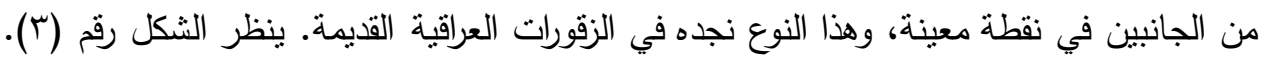

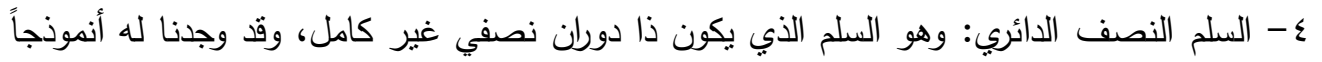
واحداً وهو من تبه كوراْ. ينظر الشكل رقم (ع).

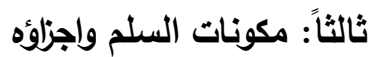

يتكون هذا العنصر العماري من عدة أجزاء ومنهات

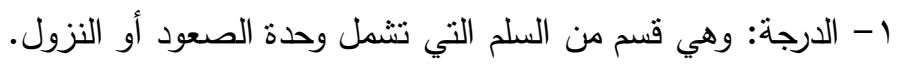

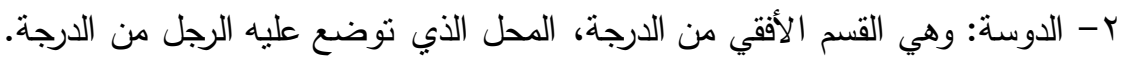
r- الرافع : وهو القسم العمودي من الدرجة والمفروض منه أن يسند حافة الدرجة الأمامية. 


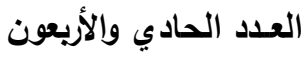

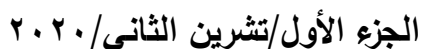

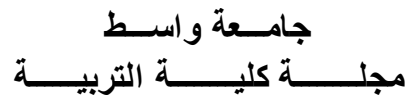

ع - الصحن: وهو عبارة عن محل استراحة في وسط السلم ، كذلك هو واسطة في تغيير اتجاه السلم في الصعود أو النزول. ه- المحجل: وهو مسند في جهة أو جهتي السلم بستتد عليه في الصعود والنزول ل. ج- الارتفاع : ويقصد به ارتفاع الدرجة أو ارتقاع الرافع. V- العرض : يقصد فيه عرض الدرجة أو الدوسة.

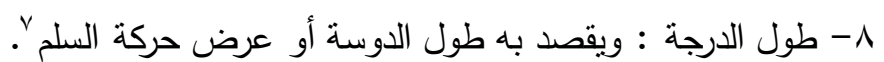

لإيعاً: اهمية استعمال السلالم

ان السلم من العناصر المهمة المكملة للأبنية القديمة، ولا يعرف بدايات استخدامه تحديداً في مجال

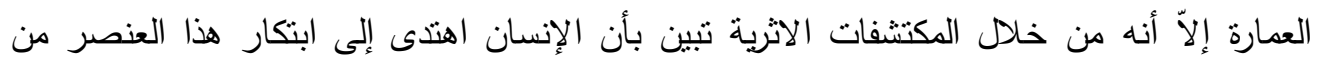

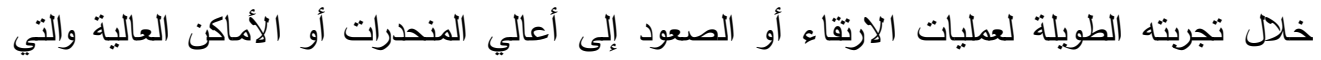

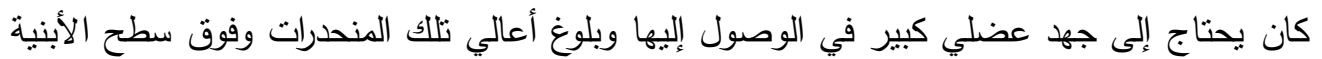
الني شيدهاء. لذا فإن أهية هذا العنصر تكمن في أنه سهل عملية الصعود إلى أعالي السطوح

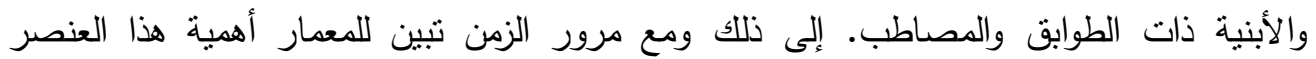

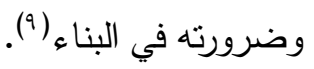

المبحث الثاني

ا اهم استعمالات السلالم

اولاً: استعمال السلالم في عمارة البيوت السكنية السلام

تعتبر السلالم من العناصر المعمارية المهمة التي استخدها المعمار في مبانيه وقد سبقت

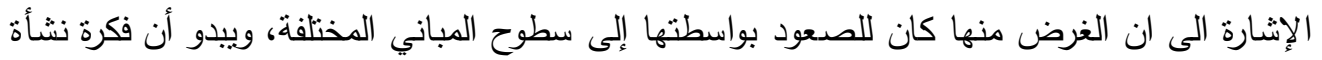

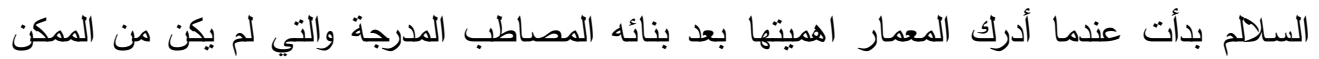

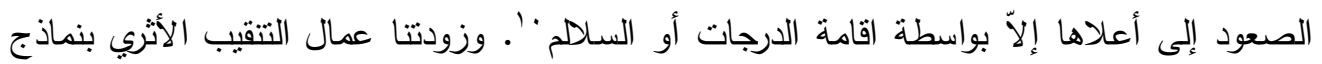
عن السلالم المكتشفة في المواقع القديمة، على الرغم من بعض الصعوبات التي نواجه دراستها وذلك الكا

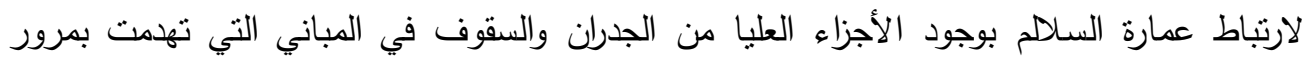


العدد الحادي والأربعون

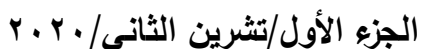

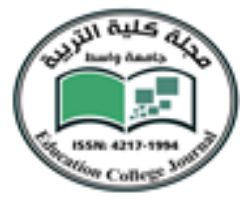

ان اقدم دليل على وجود السلالم المستخدم في البيوت السكنية كثف عنه في موقع ام الدباغية والني تعد من القرى المهمة العائدة بتاريخها إلى العصر الحجري الحديث، وتبين من نتيجة الكثف في

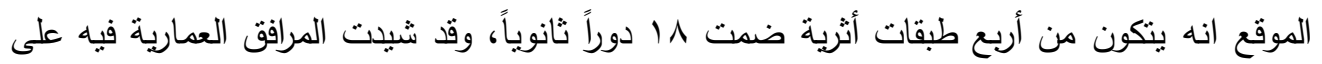

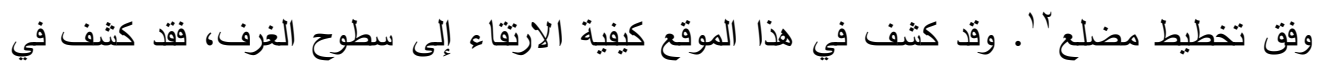

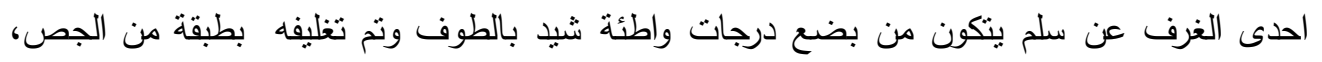

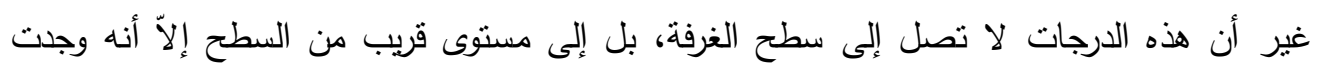
بعض الحفر أو النقوب الموجودة في داخل الجدران كان يمكن الوصول من خلآلها إلى الـى السطح

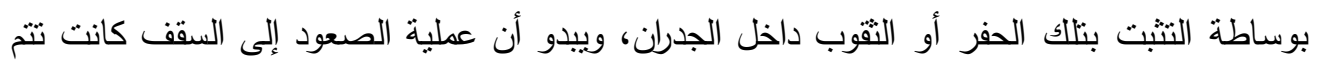

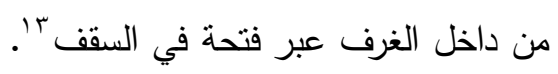
ان هذا النموذج البدائي من السالم نه صمم بصورة بسيطة، لم تكن عملية بدرجة كبيرة في

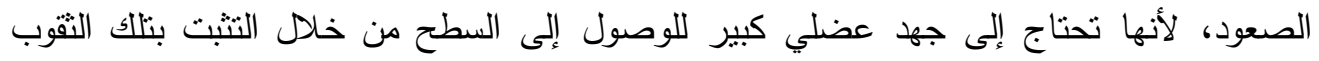

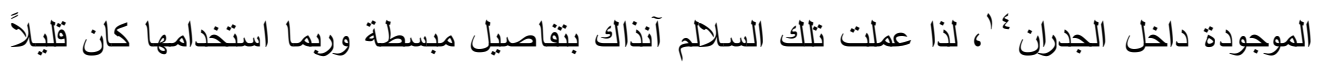

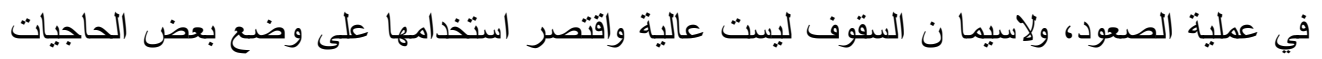
المنزلية عليها وعلى الأغلب لنكون بعيداً عن منتاول الأطفال مما يعني محدودية استخدامها كدرج الهن

وفي موقع تل الصوان العائد الى (الألف السادس ق.م) كثف عن نموذج لسلم ينكون من خمس

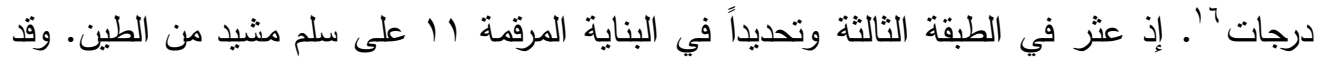

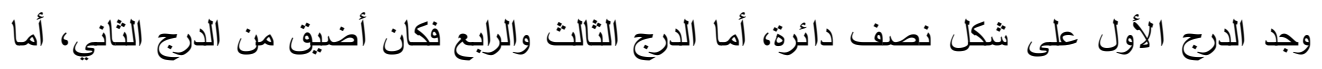

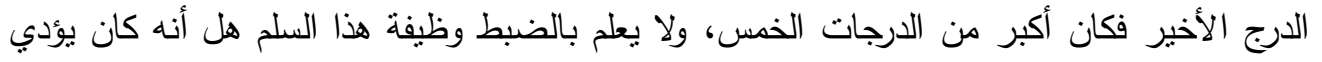

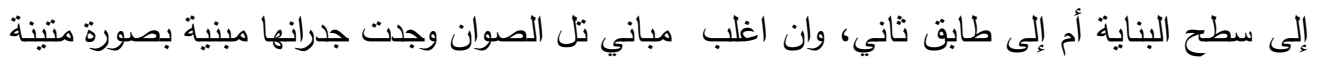

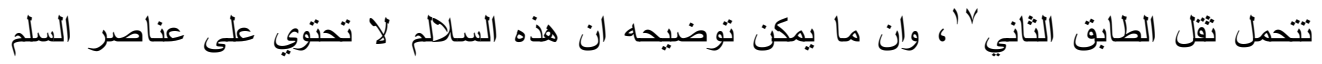

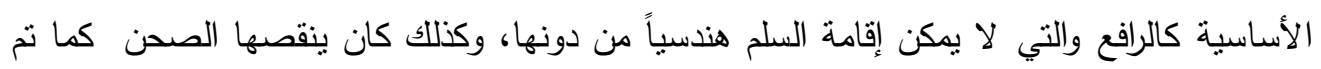

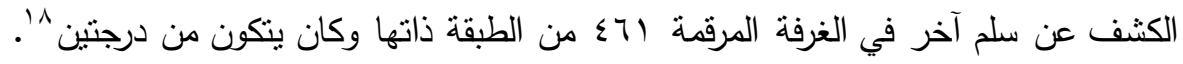

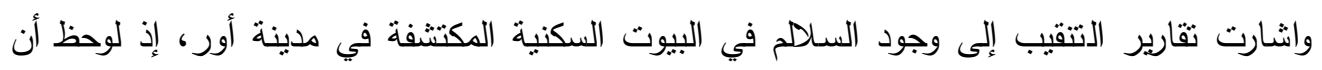
المخطط الأساس للبيت السكني يتضمن ساحة وسطية يحيط بها قاعات وغرف تتكون من طابقين ينت

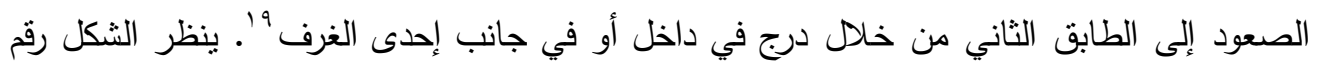

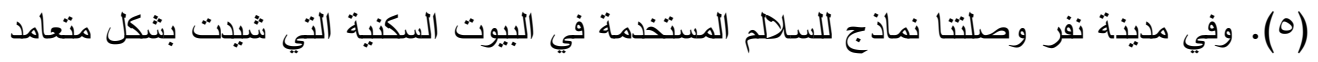


العدد الحادي والأربعون

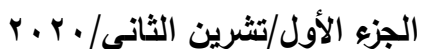

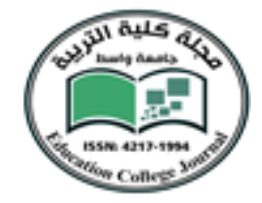

مع بعضها البعض وذات أساس مثين وسميك كما لوحظ وجود ساحة أو باحة مركزية تتظظم حولها

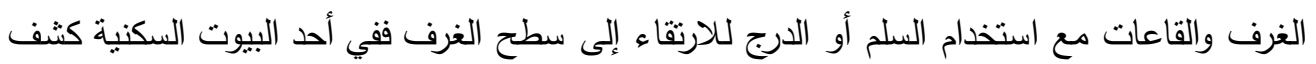

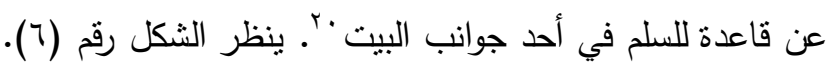

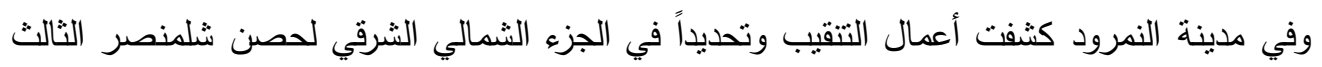

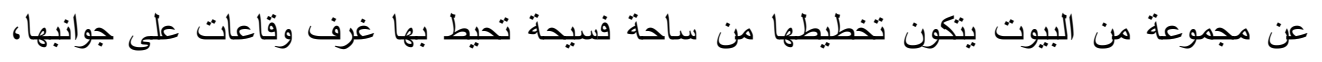

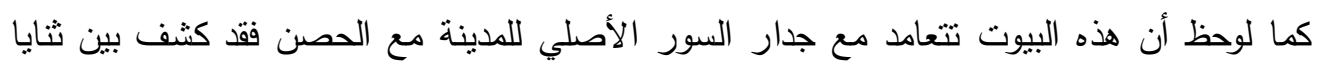

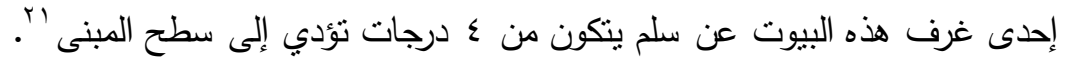

ثانياً: استعمال السلالم في عمارة المعابد استعمل عنصر السالم في المباني الدينية، وتعكس أعمال التتقيب عن تطور عمارة المعابد بمرور

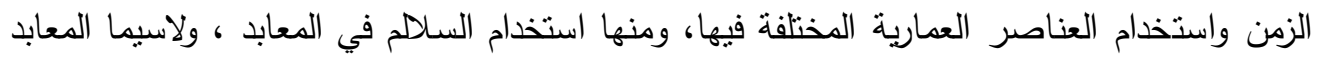

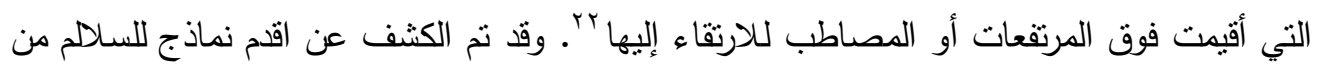

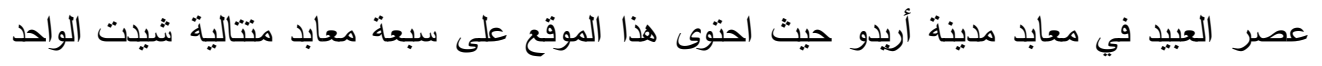

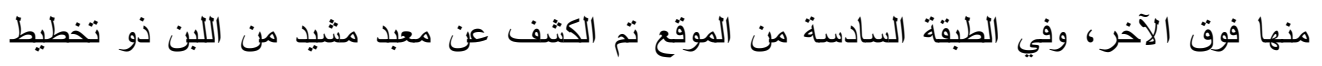

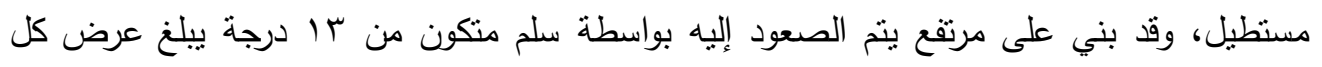
درجة ام تقريباً ويبلغ الطول الكلي للسلم مم، وفي المعبد نفسه استخدم المعمار السلالم في أحد

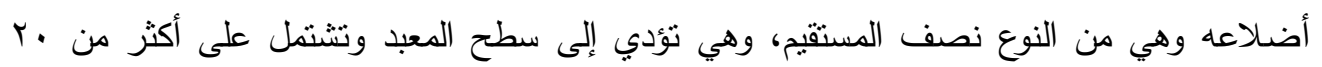

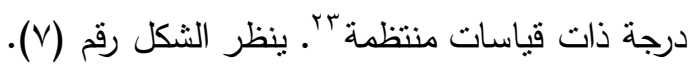

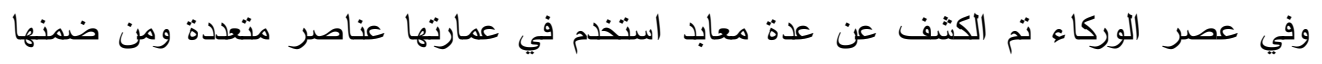

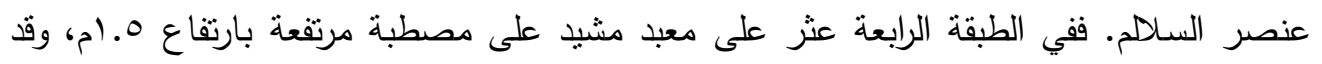

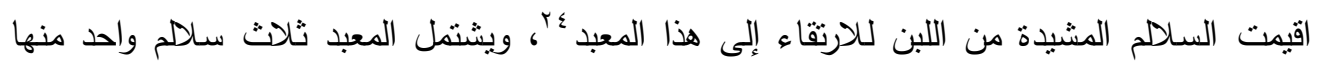

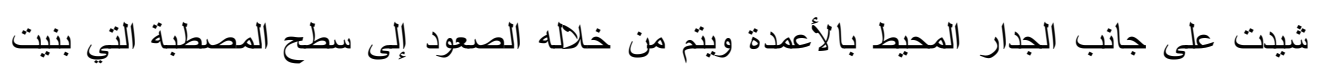

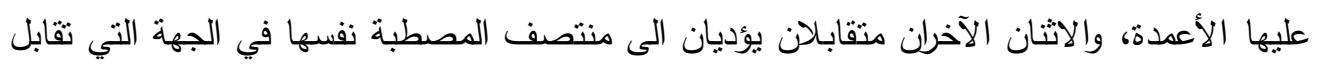

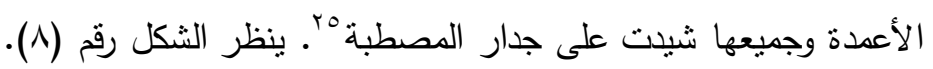
وكثف في تل العقير عن معبد كبير يقوم على مصطبة بارتفاع ع أمتار وقد أقيم المعبد على دكتين

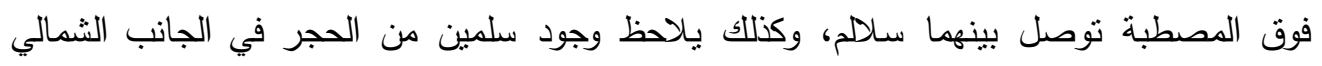

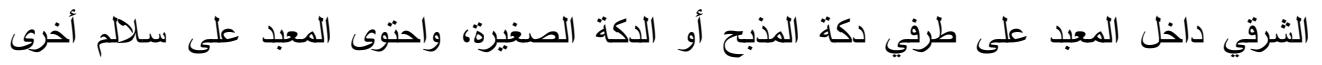


العدد الحادي والأربعون

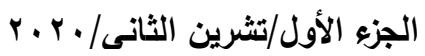

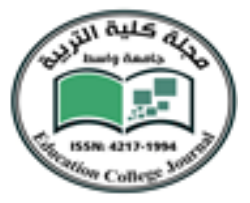

شيبت ضمن البناء الداخلي للمعبد وكثف في الضلع الثرقي عن سلم مستقيم بالقرب من الجدار

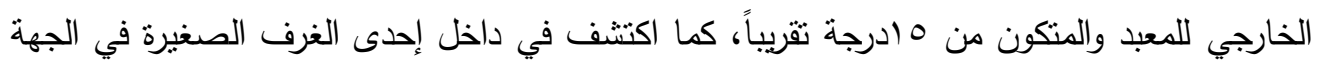

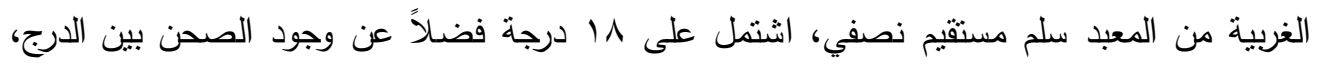

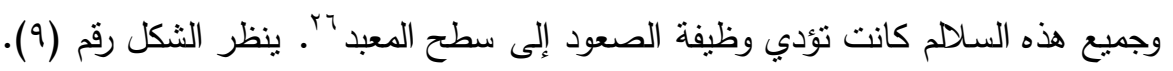

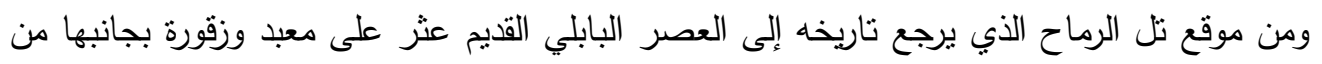

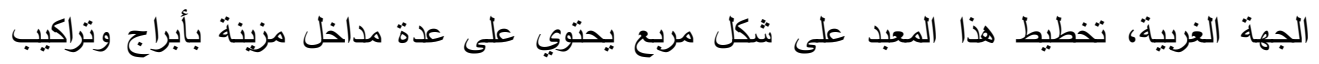

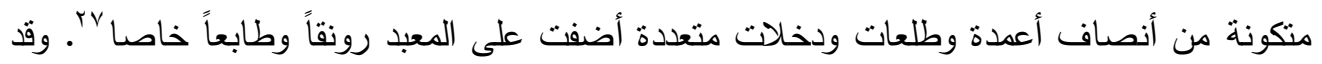
تم العثور على سلم في الزاوية الثمالية من المعبد يتم من خلالها الارتقاء إلى الزقورة الملاصقة

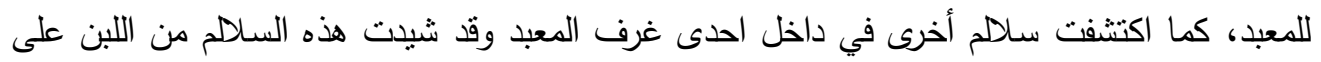

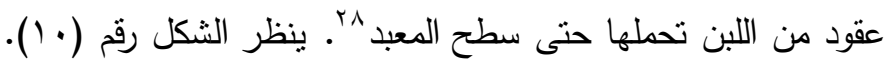

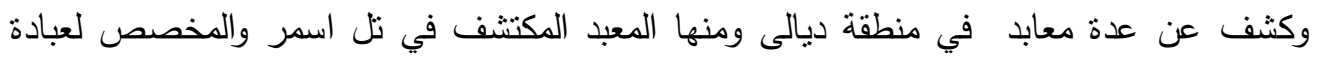

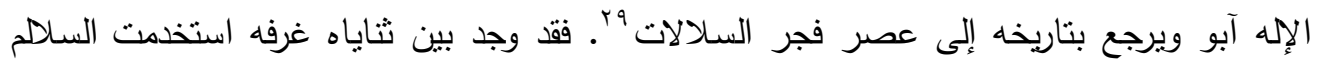

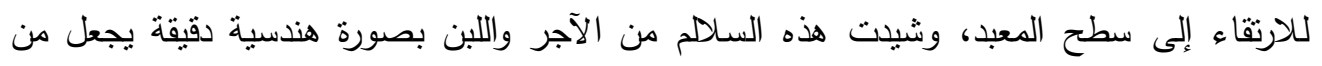

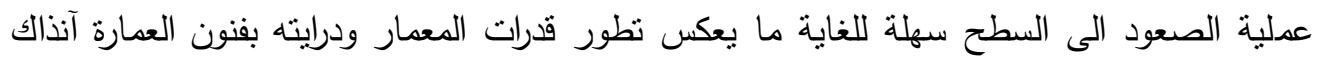

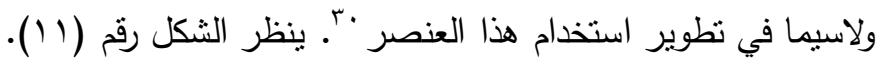

ثالثاً: استعمال السلالم في الزقورات اسفرت نتائج التنقيب الاثري عن كثف عنصر السلالم في الزقورات، وكانت تعد الاعنصر الاساس

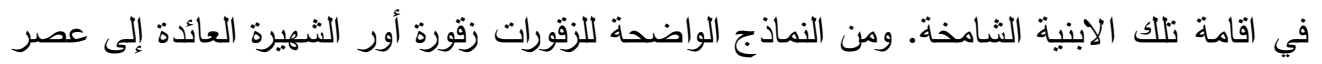

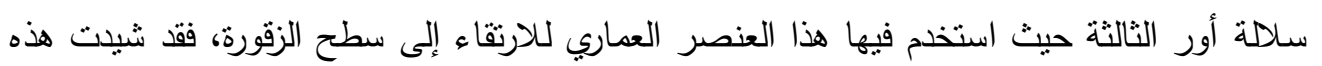

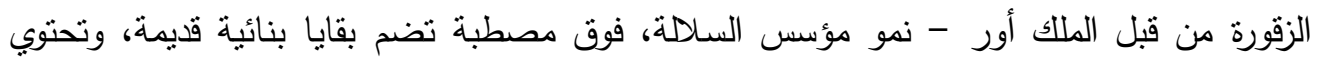

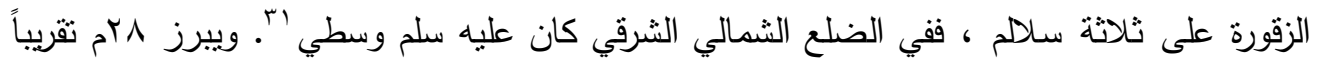

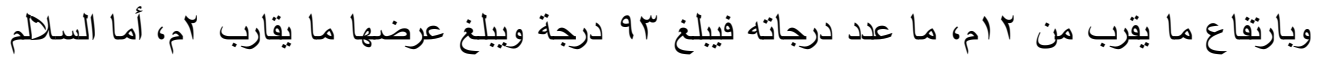

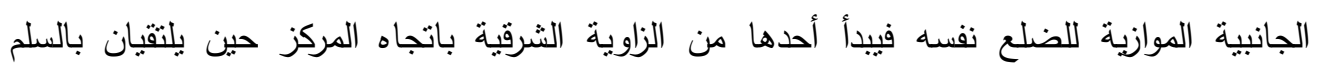

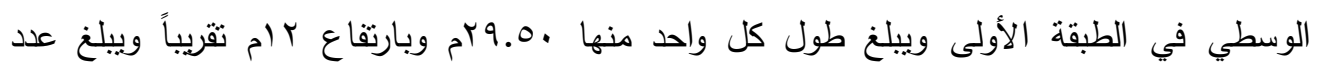

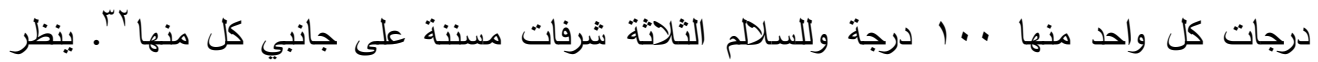

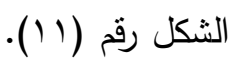


العدد الحادي والأربعون

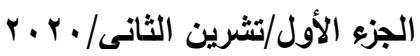

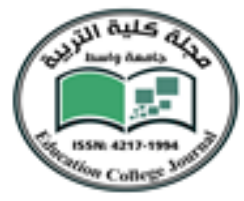

ان أهم ما تم كثفه في مدينة بابل من عمائرها زقورتها في الجزء الثمالي من معبد الاله مردوخ،

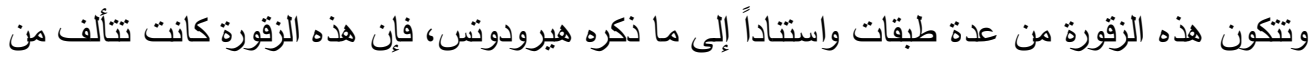

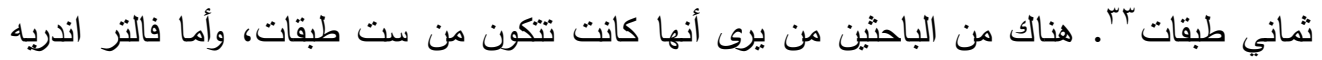

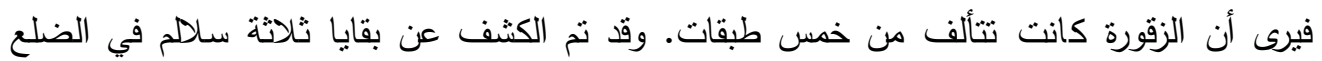

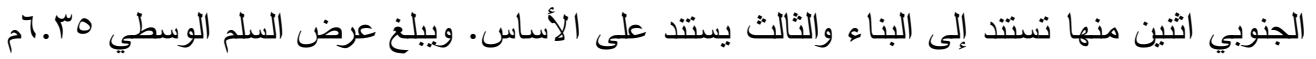

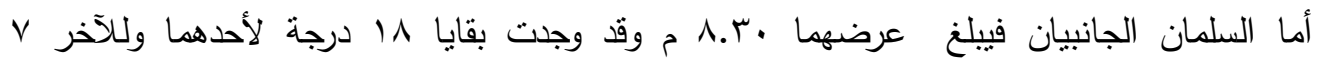

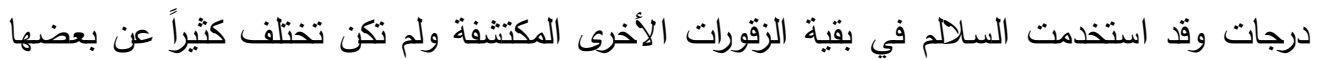

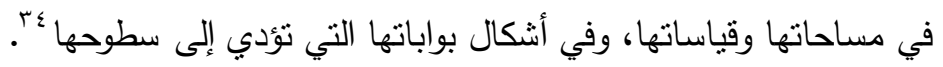

\section{رابعاً: استعمال السلالم في القبور}

ان هذا العنصر المعماري المهم استخدم في القابر القديمة في بلاد وادي الرافدين، ومن النماذج التي وصلتتا من المقابر مقبرة أور الملكية، إذ شيد السلالم التي تؤدي إلى داخل المقبرة، وتشتنل هذه

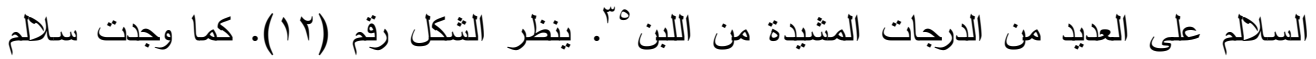
مستخدمة في المقابر الثمالية، فتم الكثف عن سلالم شيدت داخل المقابر الملكية في مدينة النمرود، ومنها المقبرة الرابعة حيث احتوى مدخلها الرئيس على عدة درجات يتم النزول من خلالها إلى داخل

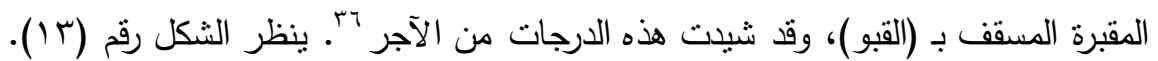

\section{خامساً: استعمال السلالم في القصور}

تعتبر فكرة اعتماد أو استعمال الطابق العلوي في البيوت السكنية أو المباني الأخرى فتح المجال أمام الملوك بتجسيد وظيفة هذا العنصر في قصورهم، فاستخدام عنصر السلالم، ومن المعروف أن عمارة القصور خاصة القصور الآثورية أقيمت على مصاطب التي استلزمت استخدام السلالم للارتقاء

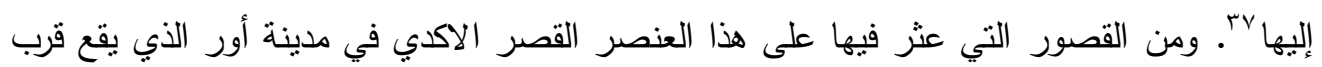

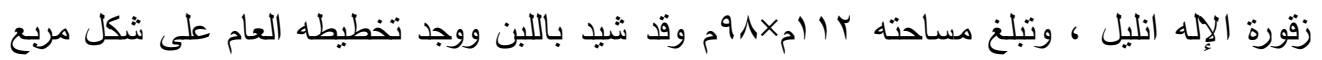
ينكون من ساحة وسطية تتوزع على جوانبه قاعات وغرف القصر، أما المدخل الرئيس فيقع في

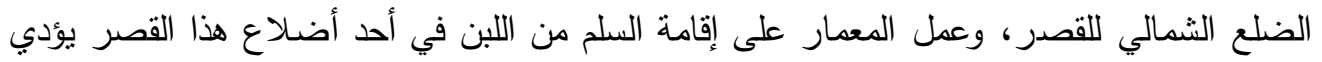

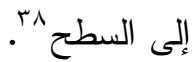


العدد الحادي والأربعون

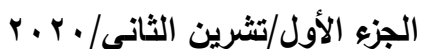

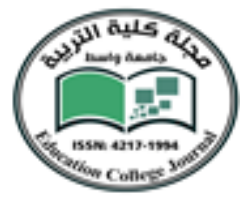

وفي العصر البابلي القديم اكتشف قصر فخم من مدينة ماري هو قصر الملك زمري ليم وقد امتاز هذا القصر بكثرة الغرف والقاعات فيه، الني تقارب من ..r غرفة وقد لاحظ المنقبون استخدام المعدار للسلالم بين أجزاء هذا القصر ومنها القاعات التي شيدت على الدصاطب لارتقاء إلى لهي

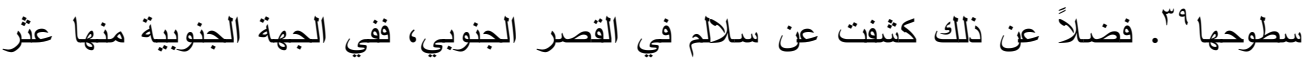

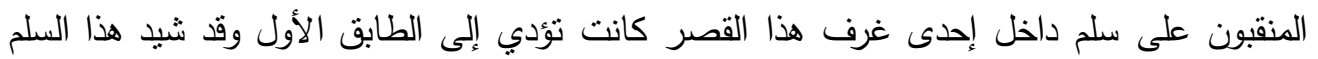

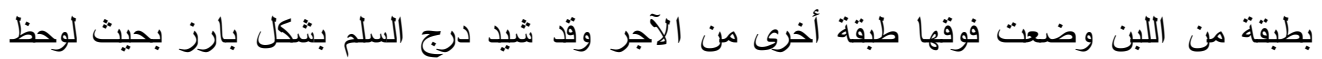

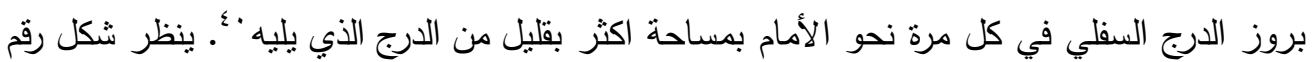

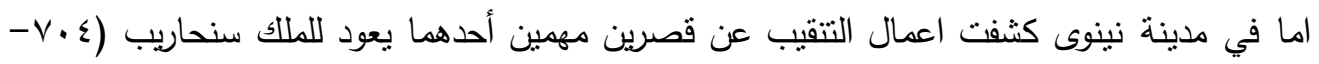

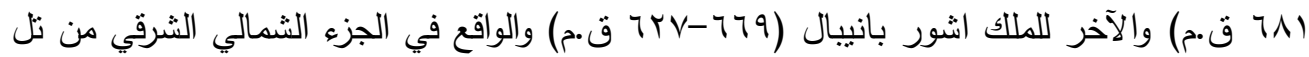

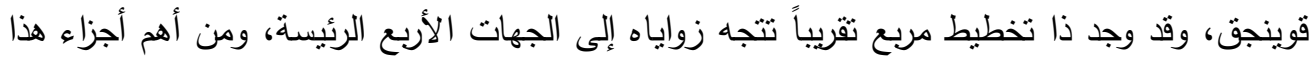
القصر قاعة العش التي كان لها ثلاثة أبواب، نطل على الساحة الرئيسة للقصر وكان ينم الارتقاء

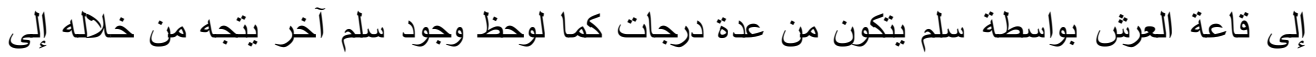

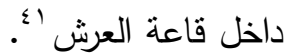

الاستنتاجات 1- ان عنصر السالم من العناصر العمارية الهمة في ابنية بلاد الرافدين القديمة، ولم يدرس دراسة علمية اثارية منكاملة بل لاتزال هناك الكثير من جوانب هذا العنصر غامضة.

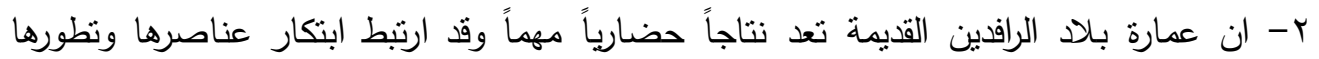

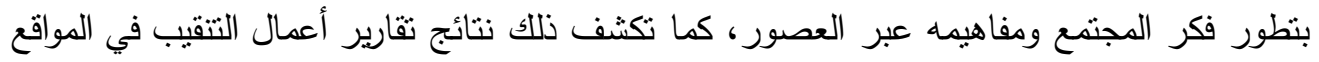
المختلفة والمعلومات المنوافرة عنها. r- ابدع المعمار الرافديني القديم، وطور تقنية تنكيلة المباني وعناصرها، وأصبحت لديه معرفة الدانة

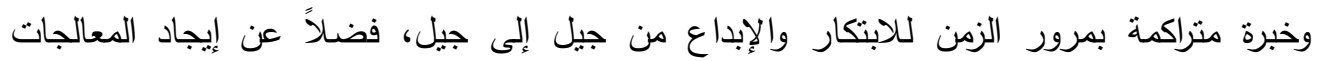
الإنشائية لكل عنصر وديمومتها وقدرتها على مقاومة عامل الزمن والظروف المناخية. ع- تضم العمارة الرافدينية القديمة عناصر عمارية كثيرة ومتعددة، من اهمها عنصر السلالم بالإضافة الى عناصر عمارية اخرى منها: العقود، والطلعات والدخلات، والاعدة، والاقبية. 


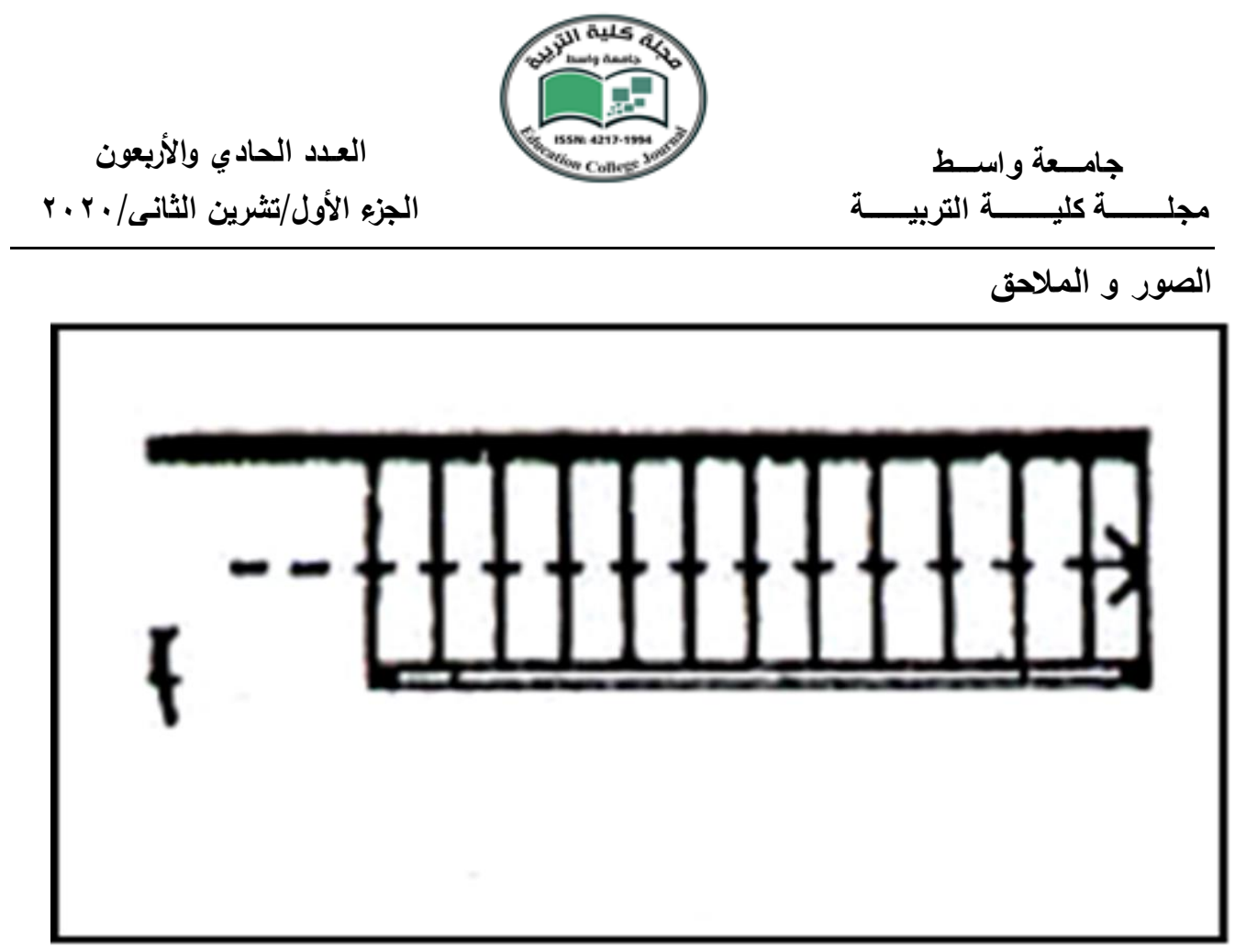

الثكل رقم ( ) - (1) السلم المستقيم

مأخوذ من: ئاري، خليل كامل، المصدر السابق.

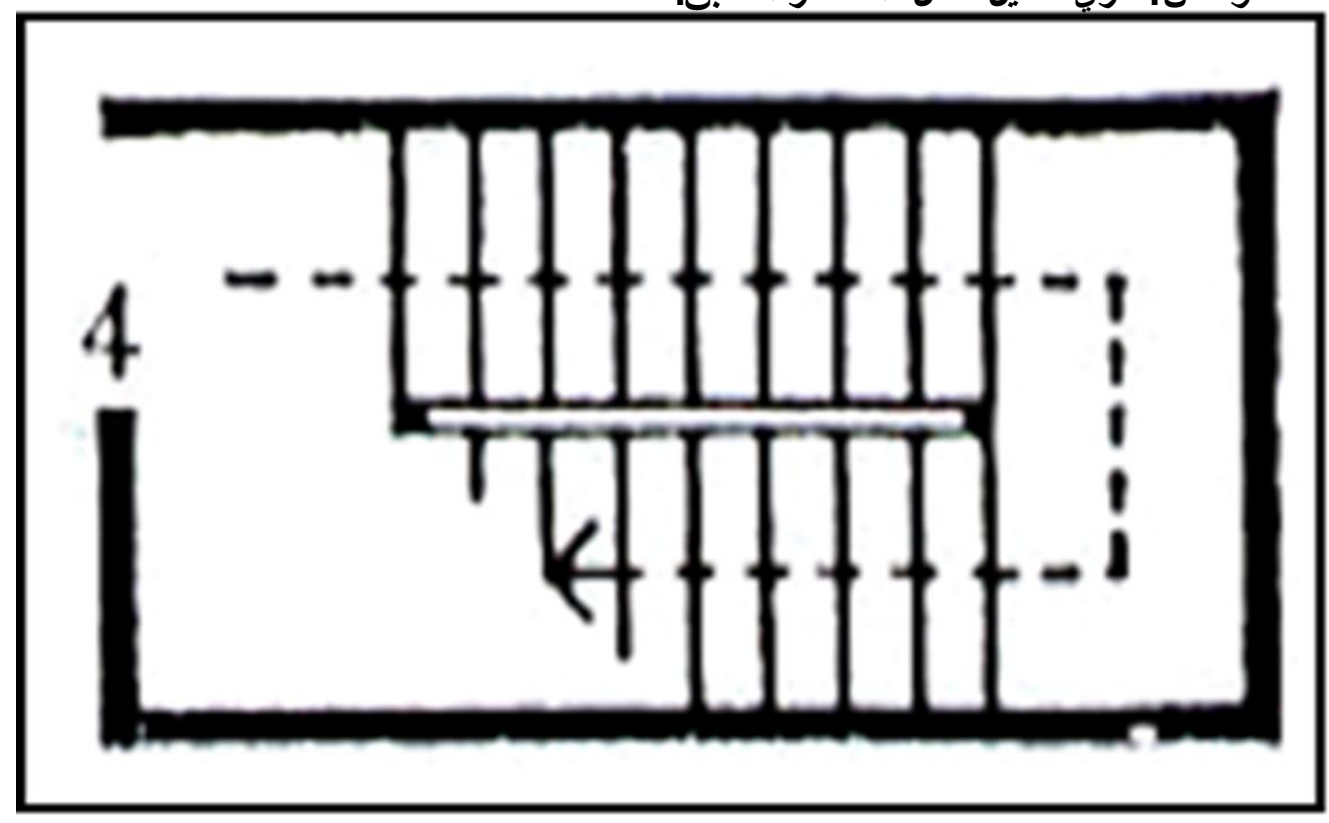

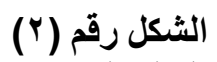

السلم المستقيم النصفي ماني

مأخوذ من : ئاري، خليلّ كامل، المصدر السابق. 

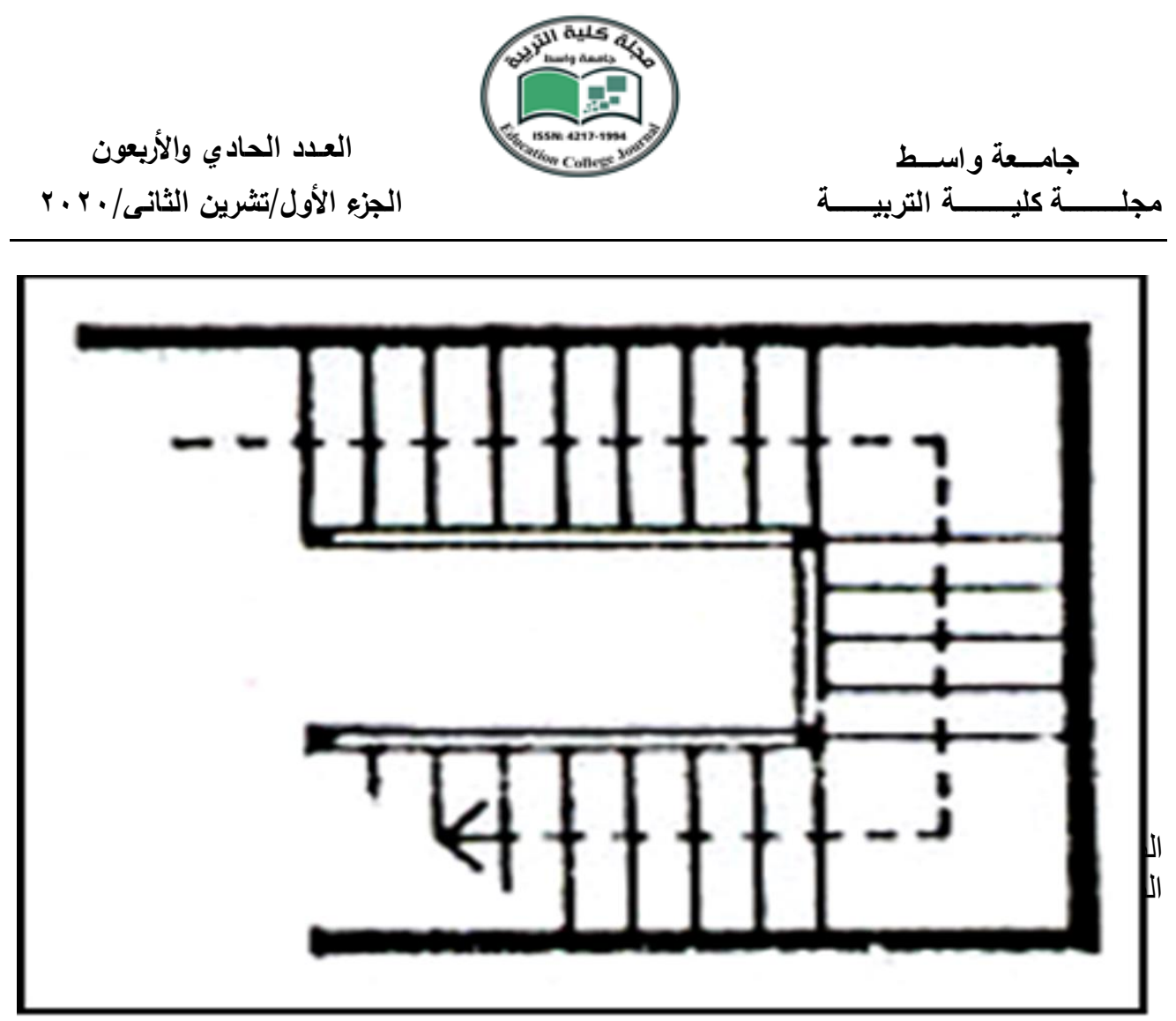

مأخوذ من: ئاري، خليل كامل، المصدر السابق.

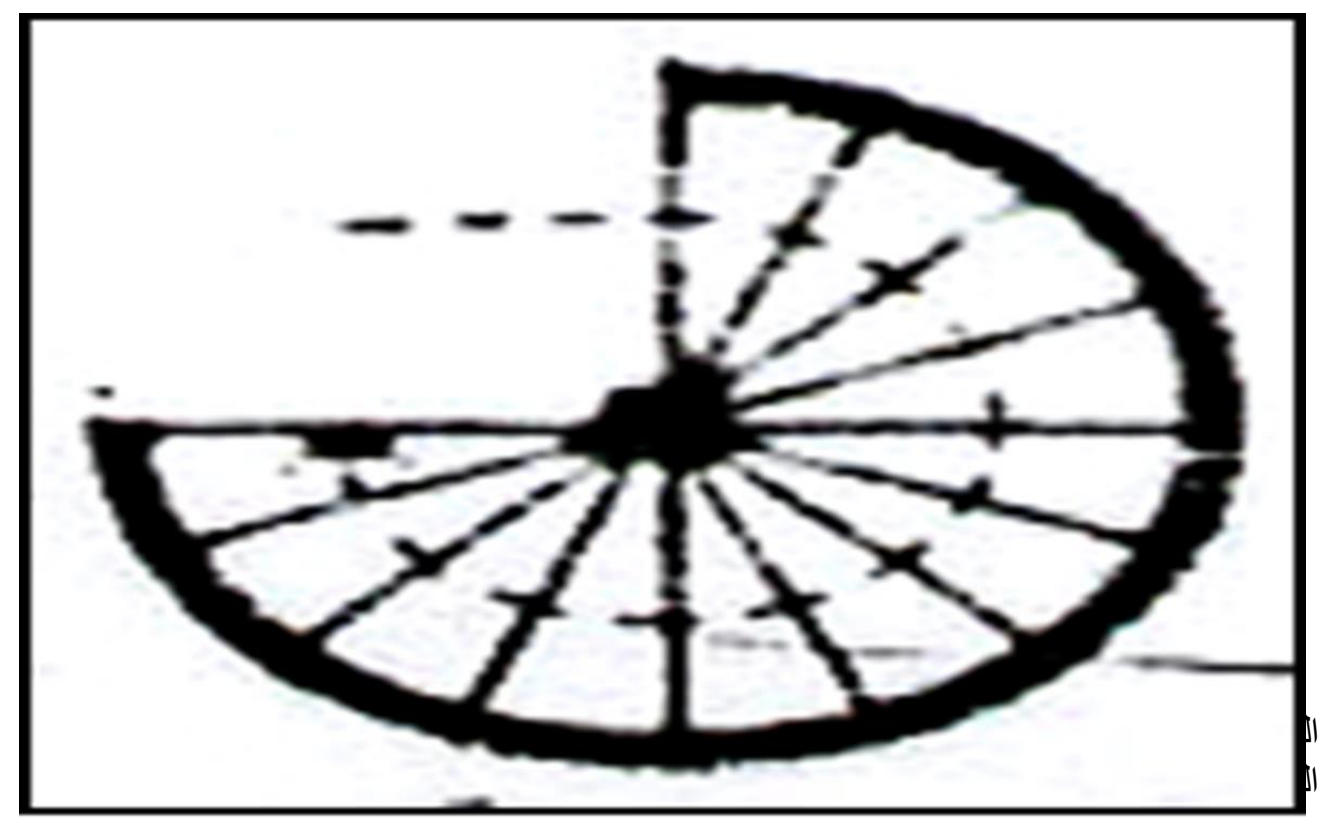

مأخوذ من: ئاري، خليل كامل، المصدر السابق. 

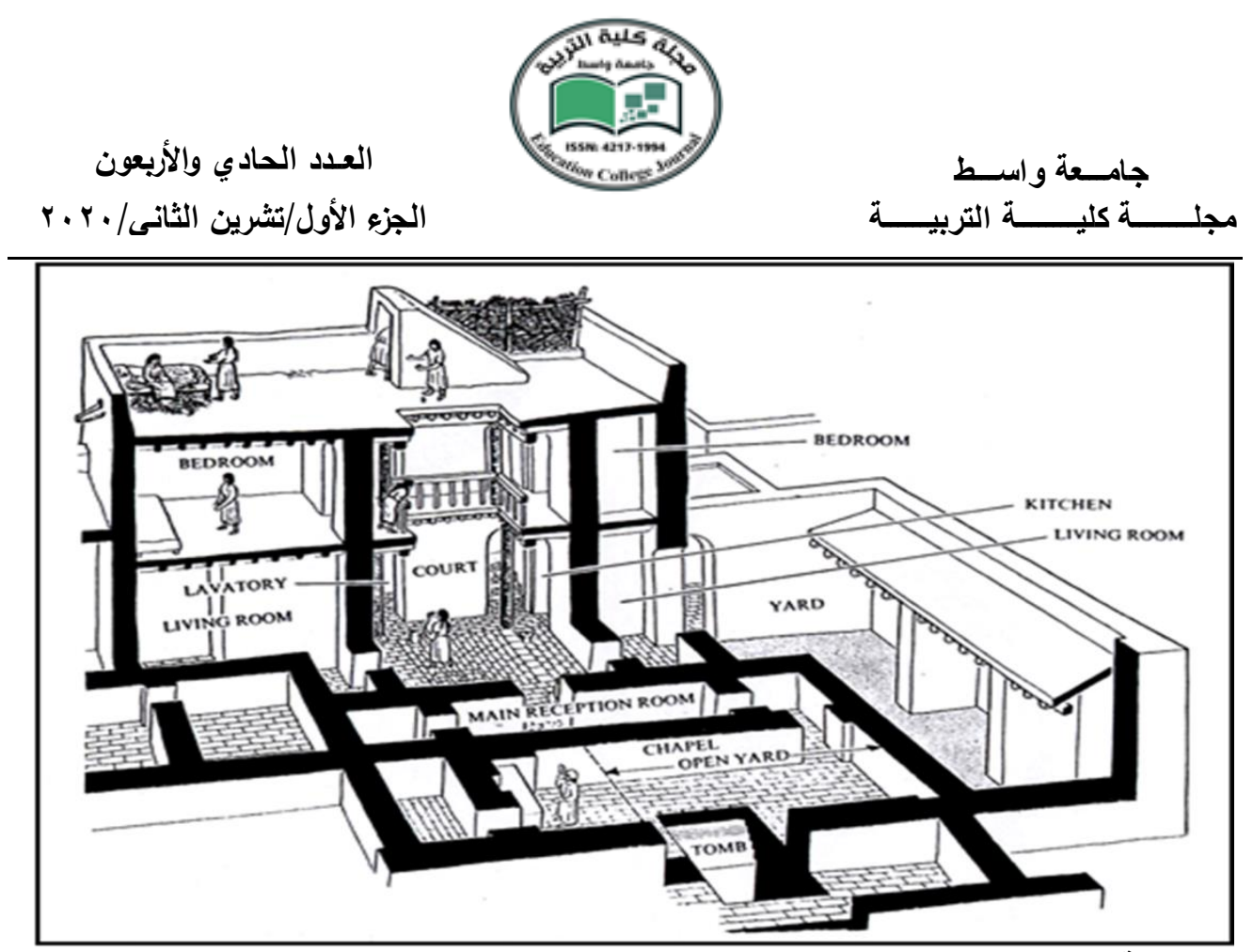

الشكل رقم (0)

Wolley, L, Excavation at Ur, Op. Cit.

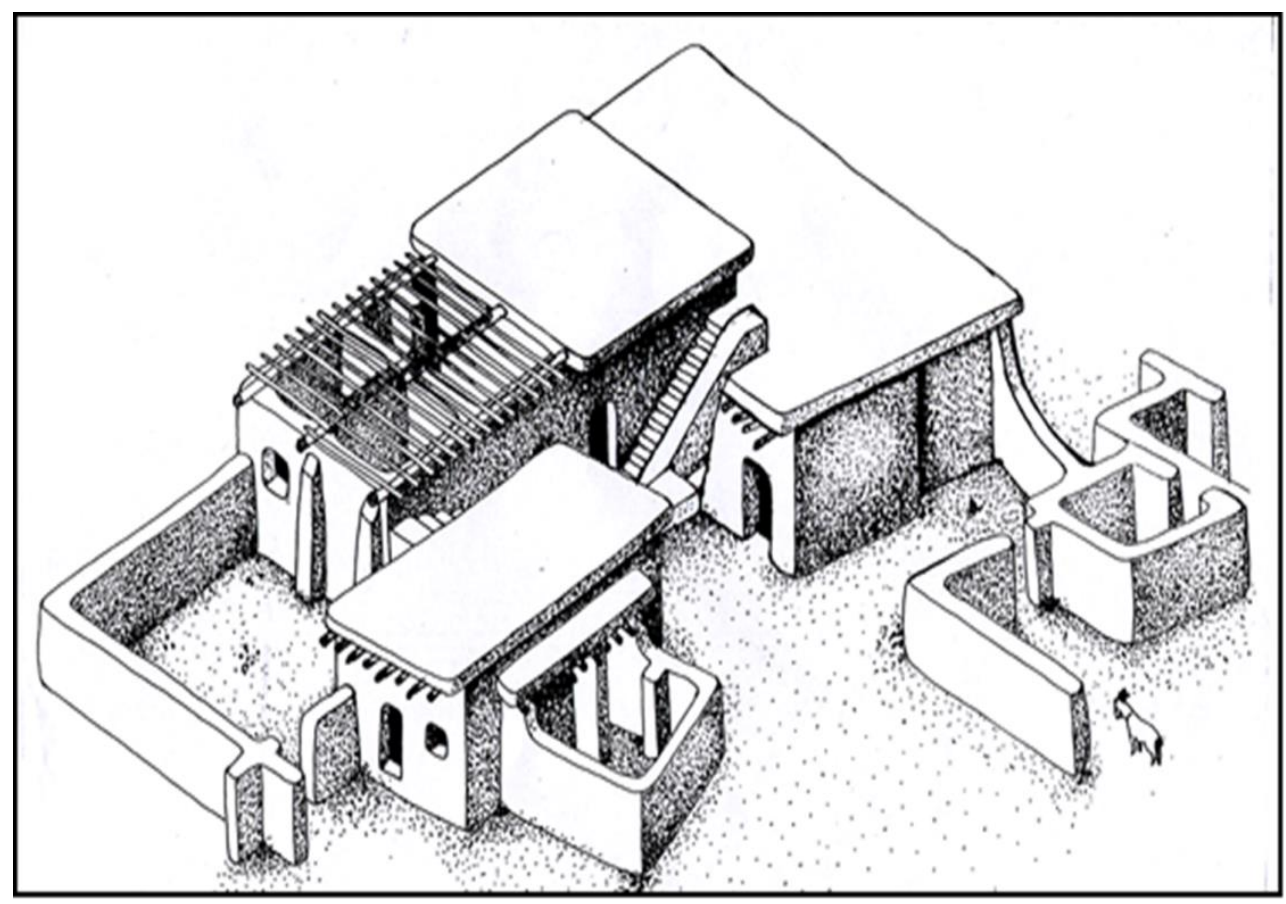

الشكل رقم (7)

Oates, D. Op. Cit. 


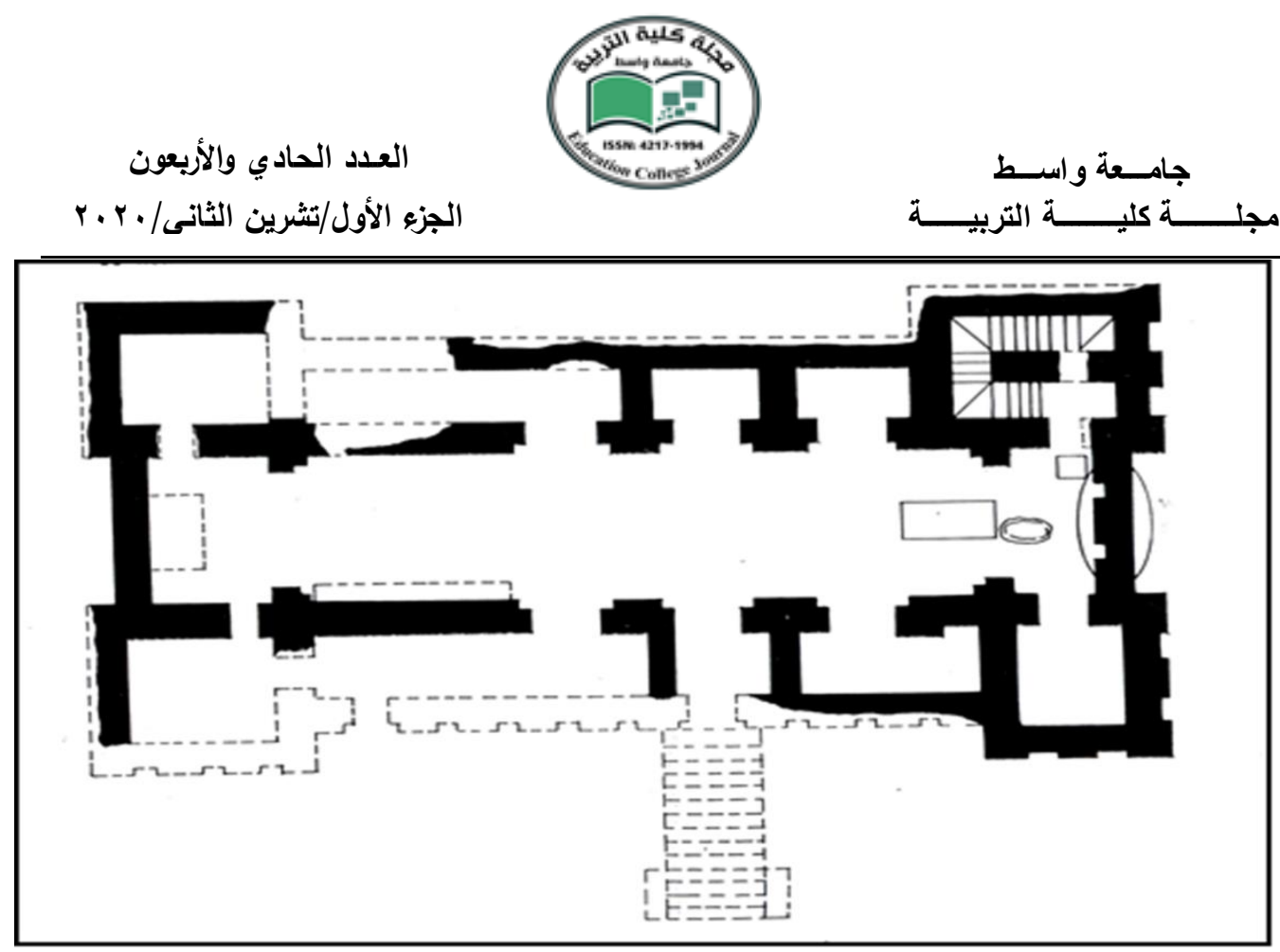

الشكل رقم (V)

Oates, D. Op. Cit.

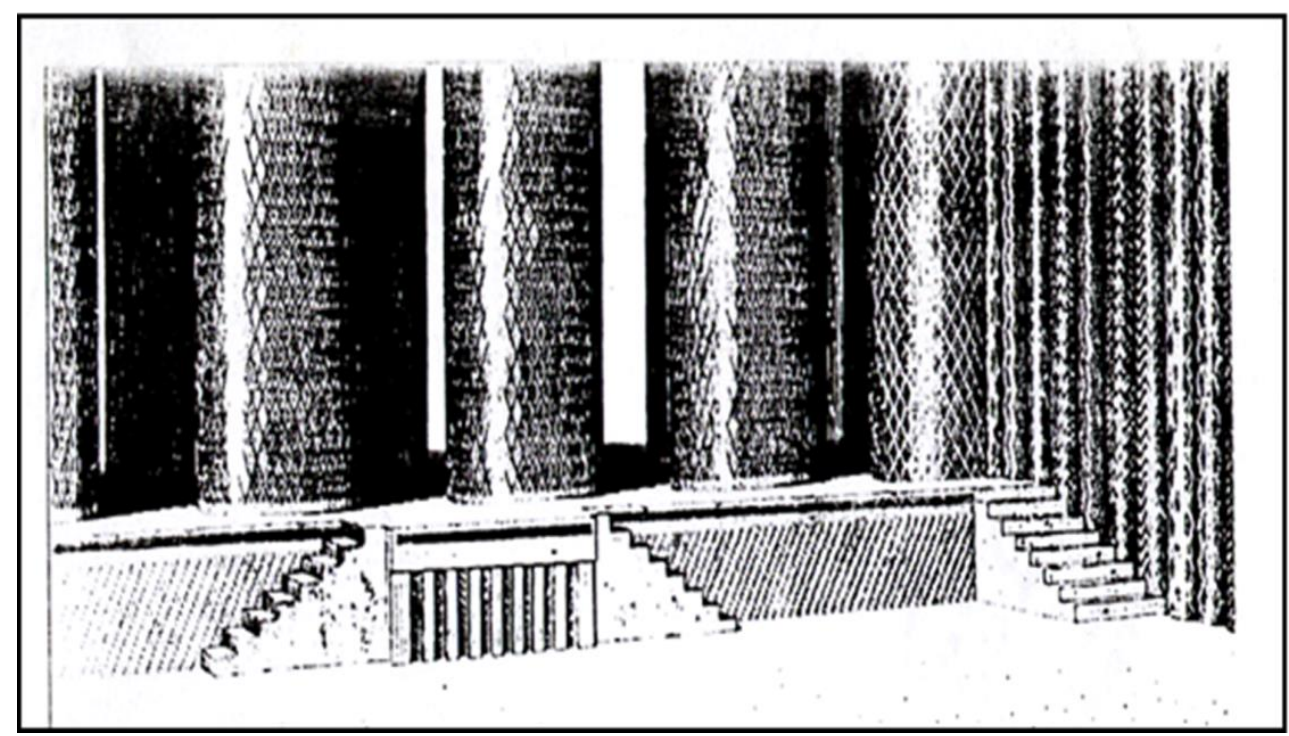

الشكل رقم (^)

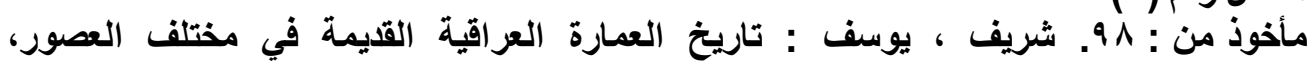

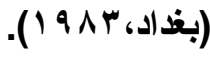



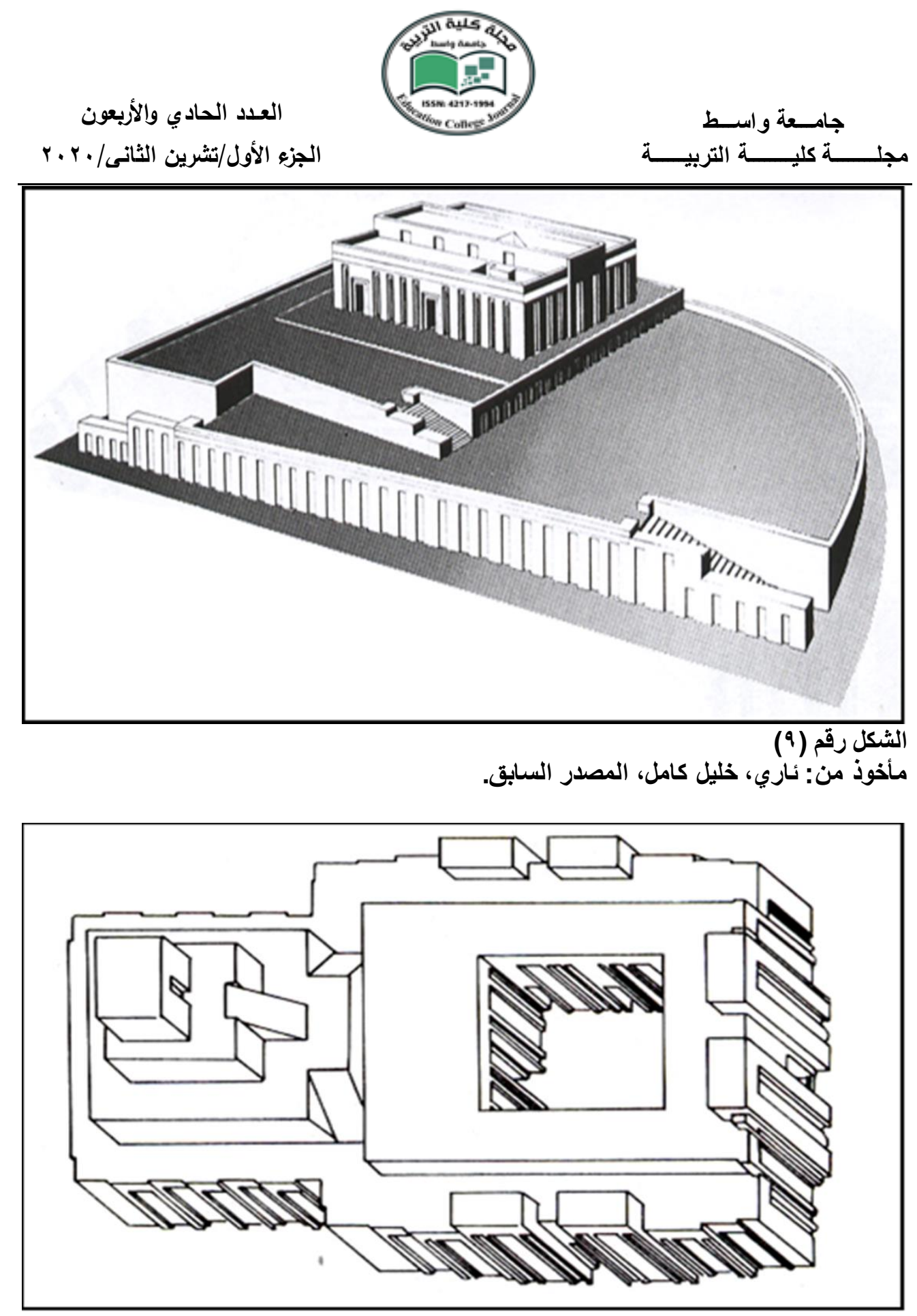

الشكل رقم (·)

Frankfort, H, Op. Cit. 

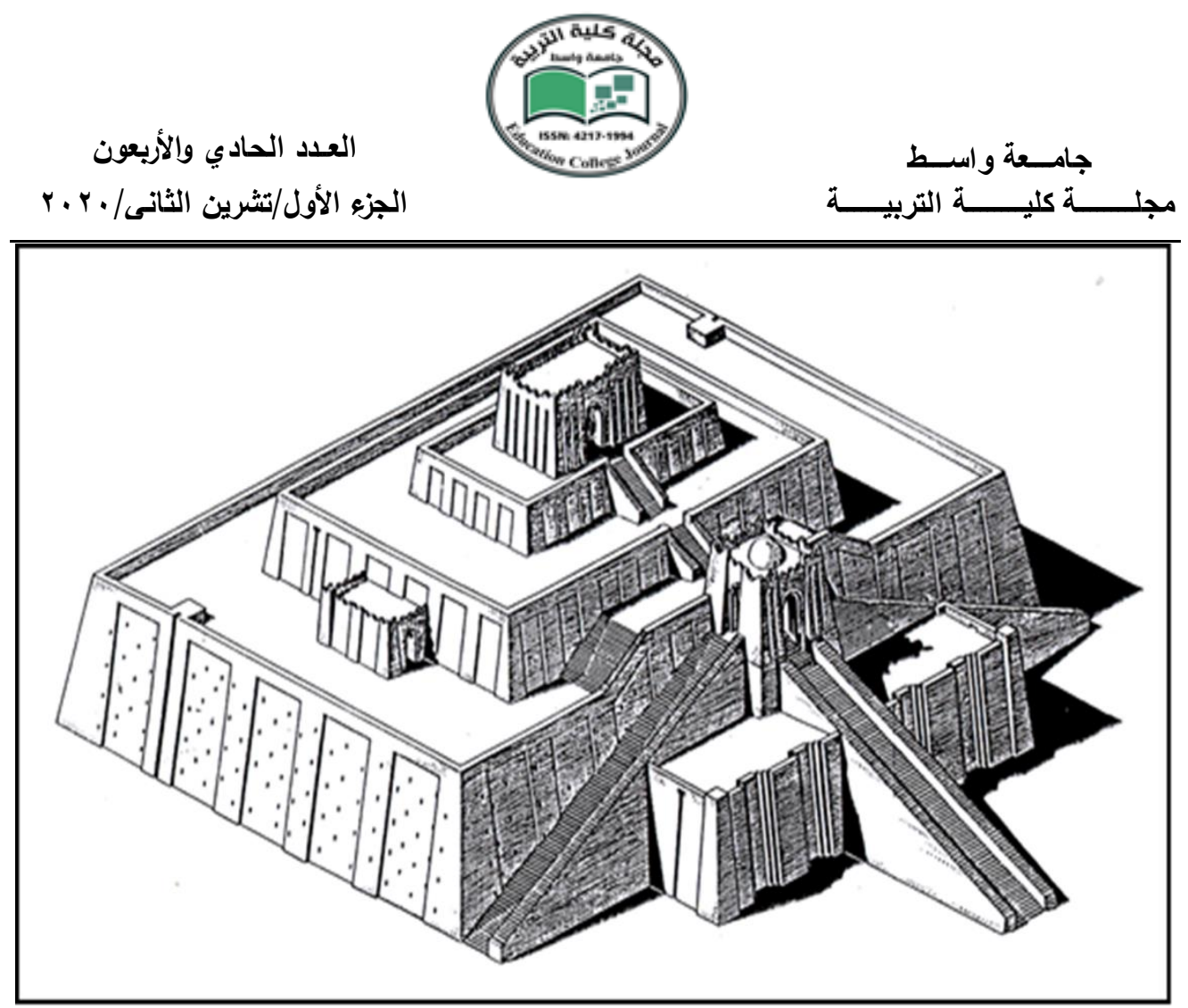

الشكل رقم (1)

مأخوذ من: ئاري، خليل كامل، المصدر السابق.

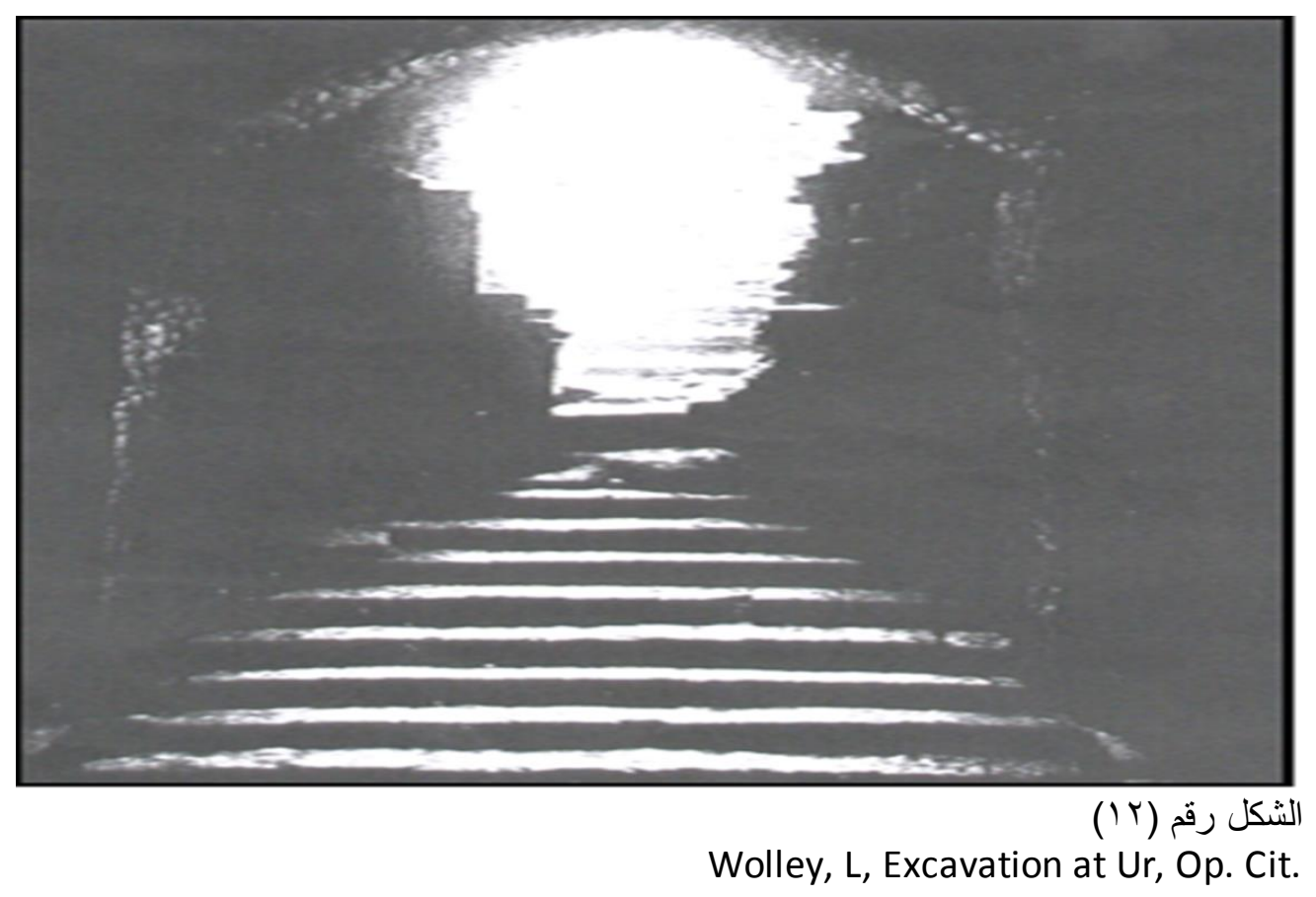




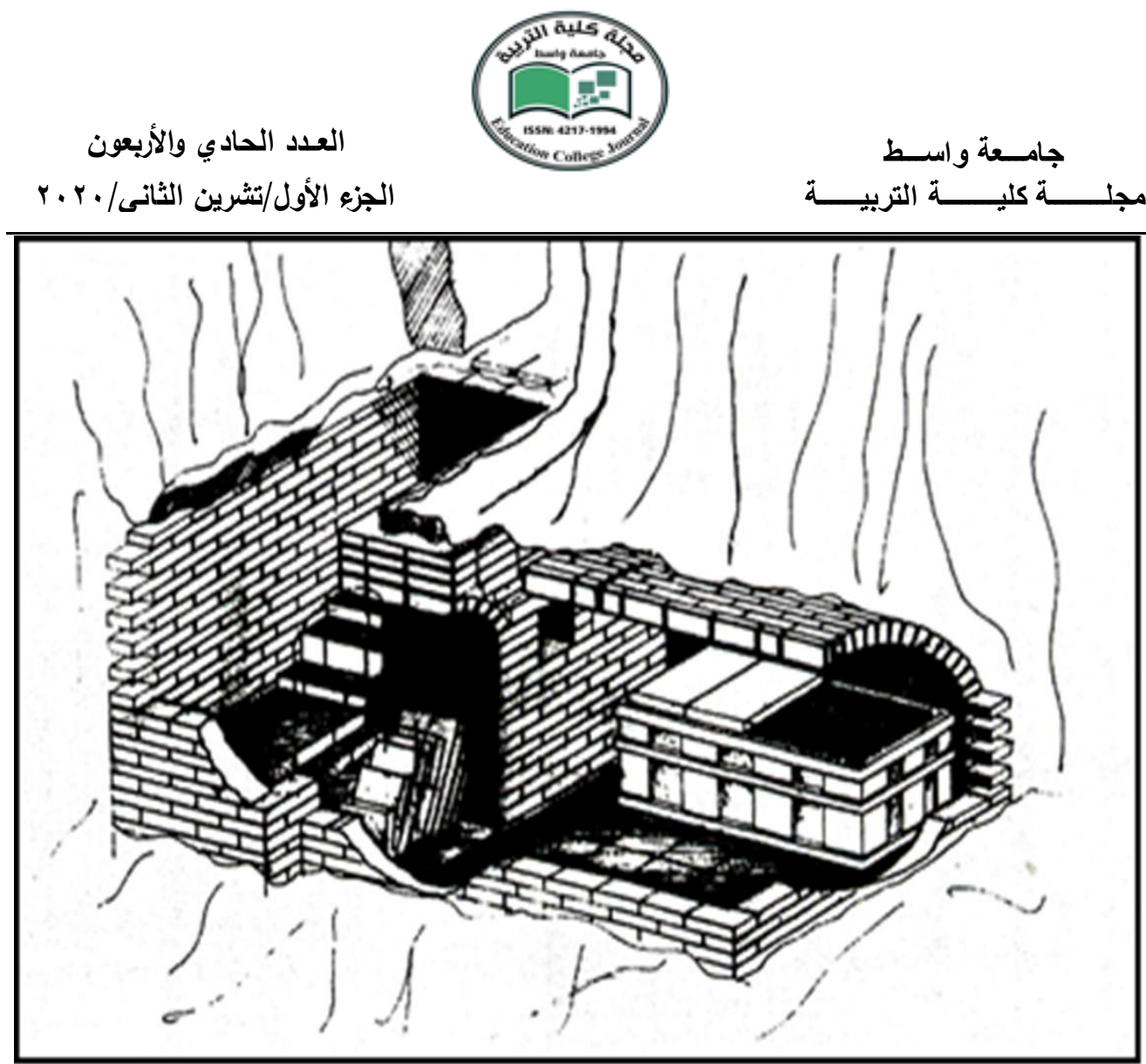

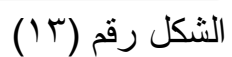
مأخوذ من: ئاري، خليل كامل، المصدر السابق.

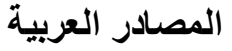

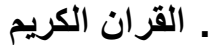

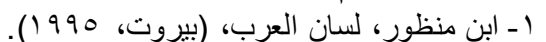

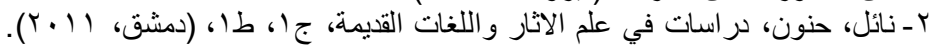

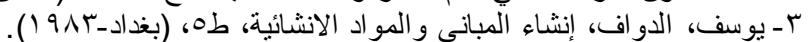

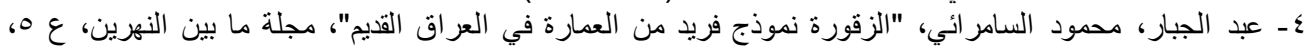

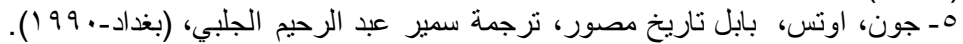

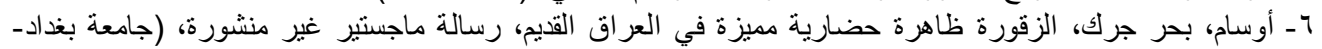

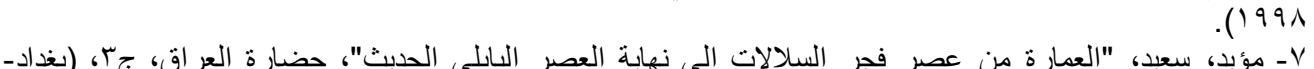
(1910

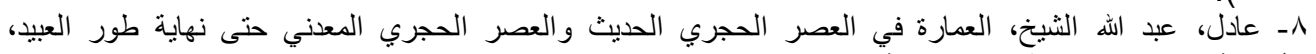

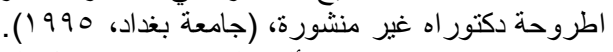

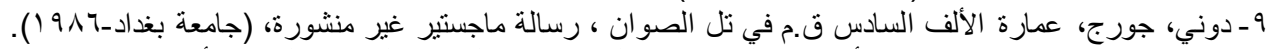

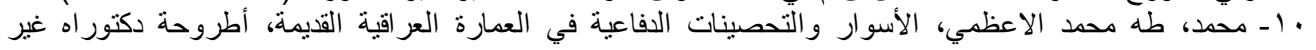

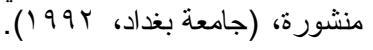


العدد الحادي والأربعون

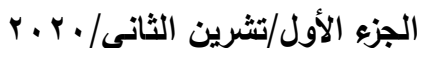

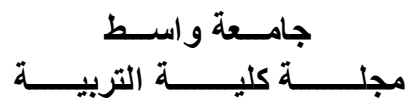

ا' إئاري، خليل كامل، اهم العناصر العمارية في ابنية العراق القيم، رسالة ماجستير غير منشورة، (جامعة الموصل، . (r...

با بـ ستيون، لويد، آثار بلاد الر افدين من العصر الحجري الحديث حتى الاحتلال الفارسي، ترجمة: سامي سعيد الأحمد،

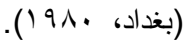

با (إ- عبد الجبار، محمود، السامرائي، "الزقورة نموذج فريد من العمارة في العراق القديم"، مجلة بين النهرين، ع ه،

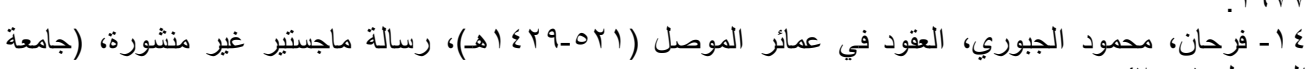

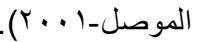
1 - شريف ، يوسف : ناريخ العمارة العر اقية القديمة في مختلف العصور، (بغداد، 1919$).$

المصادر الاجنبية

1- Von Sodden, W.: Akkad Schuss Hand Worter Bunch Wiesbaden, part 11(1959-1965).

2- Mallowan, M.E.L, "The Excavation at Nimrud (Khalhu) 1956", Iraq, Vol. X1X, 1957.

3- Kikrbirde, D, "Umm Dabaghia”, Iraq, Vol.34, 1972.

4- Yasin, W.: "Excavation at Tell Es-Sawan", Sumer, Vol. XXVI, 1970.

5- Wolley, L, Excavation at Ur, (New York-1874).

6- Margueron, J.C.: Los Mesopotamicose, (Spain-1996).

7- Frankfort, H, The Art and Architecture of the Ancient Near East.

8- Oates, D, "The Excavation at Tell Al- Rimah.

9- Plommer, H.: Ancient and Classical Architecture Simpson's History of Architecture

(Development, Vol 1, (London, 1964).

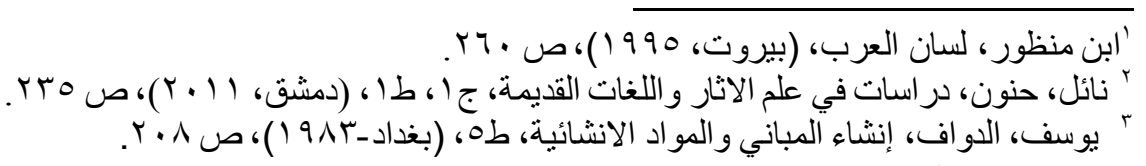

4- Von Sodden, W.: Akkad Schuss Hand Worter Bunch Wiesbaden, ), p. 221.

part 11(1959-1965

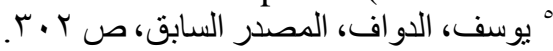

" عبد الجبار ، محمود السامر ائي، "الزقورة نموذج لون فريد من العمارة في العراق القديم"، مجلة ما بين النهرين،

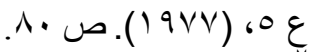

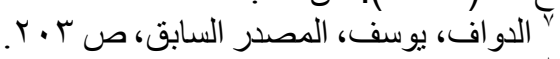

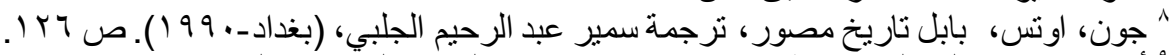

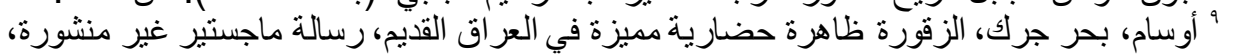

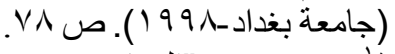

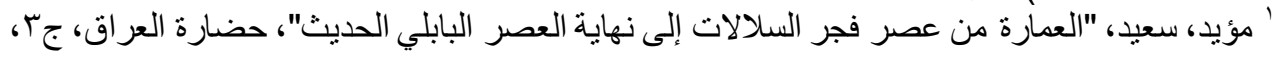

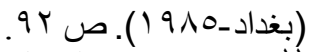

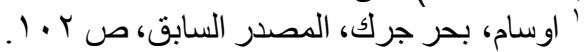

3- Mallowan, M.E.L, "The Excavation at Nimrud (Khalhu) 1956”, Iraq,

Vol. X1X, 1957, p.122

4- Kikrbirde, D, “Umm Dabaghia”, Iraq, Vol.34, 1972, p. 6.

6- Ibid, p. 7. 


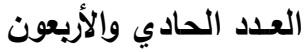

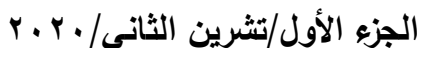

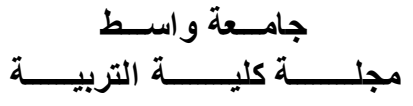

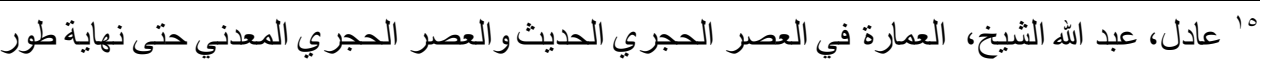

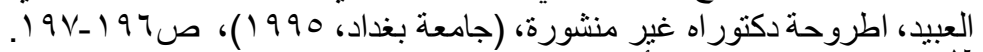

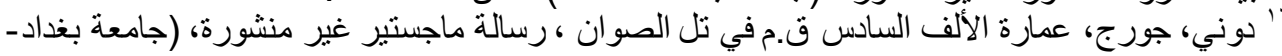

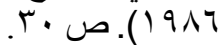

3- Yasin, W.: "Excavation at Tell Es-Sawan", Sumer, Vol. XXVI, 1970, P. 5.

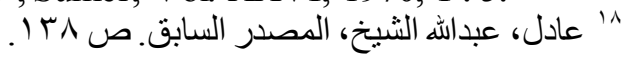

5- Wolley, L, Excavation at Ur, (New York-1874), P. 82.

6- Margueron, J.C.: Los Mesopotamicose, (Spain-1996), p. 288.

1- Mallowan, Op. Cit. 112.

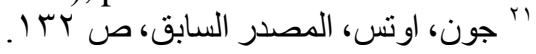

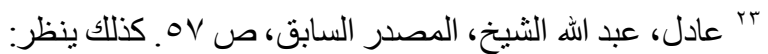

Frankfort, H, The Art and Architecture of the Ancient Near East,PP. 19-20.

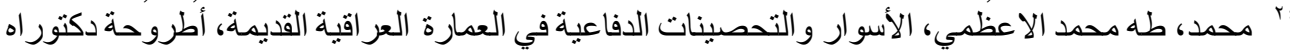

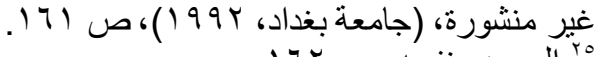

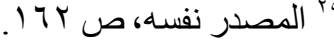

"r "ئاري، خليل كامل، اهم العناصر العمارية في ابنية العراق القديم، رسالة ماجستير غير منشورة، (جامعة

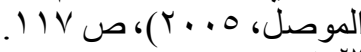

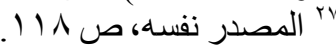

3- Oates, D, "The Excavation at Tell Al- Rimah", PP. 127-130.

"اجتيون، لويد، آثار بلاد الر افدين من العصر الحجري الحديث حتى الاحتلال الفارسي، ترجمة: سامي سعيد

Frankfort, H, Op. Cit. p. 80.

"آ عبد الجبار، محمود، السامر ائي، "الزقورة نموذج فريد من العمارة في العراق القديم"، مجلة بين النهرين، ( I L

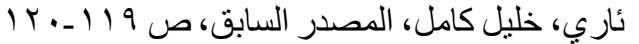

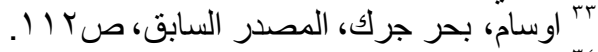

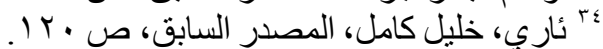

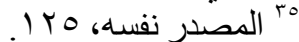

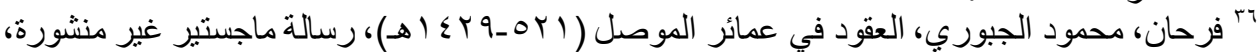

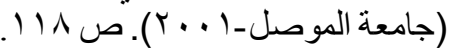

1- Plommer, H.: Ancient and Classical Architecture Simpson's History of Architecture Development, Vol 1, (London, 1964), p. 66.

3- - Plommer, H, Op. Cit, p. 89.

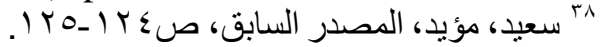

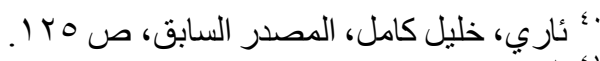

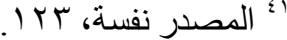

